\section{Padrões e sazonalidade do tráfego viário no município de Balneário Camboriú, SC, Brasil}

\section{Vinicius Tischer}

Escola do Mar, Ciência e Tecnologia/Universidade do Vale do Itajaí, Brasil.

\author{
Marcus Polette \\ Escola do Mar, Ciência e Tecnologia/Universidade do Vale do Itajaí, Brasil.
}

Recibido: 23 de agosto de 2018. Aceptado: 3 de abril de 2019.

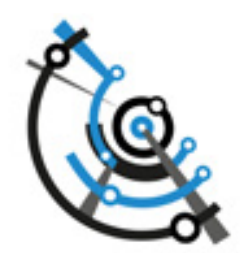

\title{
Resumo
}

A ausência de dados e informações de tráfego urbano constitui um dos principais problemas que as cidades enfrentam para realizar planejamento urbano adequado de longo prazo. O trabalho teve por objetivo investigar os padrões sazonais de deslocamento viário no município de Balneário Camboriú-SC, estabelecendo relação com a dinâmica demográfica do município. O estudo foi desenvolvido por meio de dados históricos de fluxo de veículos monitorados por radares de controle eletrônico de velocidade distribuídos em seis pontos do município. Foram analisadas a variação horária do fluxo ao longo do dia nos pontos analisados, variação diária considerando dias úteis e sazonal, ao longo dos meses e a influência dos fins de semana e feriados no fluxo de veículos. Os resultados das avaliações permitiram identificar a influência dos padrões sazonais nos pontos de estudo, identificar horários e fluxos de pico, dias de maior movimento e a influência de fins de semana e feriados.

\section{Patterns and seasonality of road traffic in the city of Balneário Camboriú, SC, Brazil}

\begin{abstract}
The absence of urban traffic data and information is one of the major problems that cities face in order to adequate long-term urban planning. The purpose of this study was to investigate the seasonal patterns of traffic displacement in the municipality of Balneário Camboriú-SC, establishing a relationship with the demographic dynamics of the municipality. The study was developed using historical vehicle flow data monitored by electronic speed control radars distributed in six points of the municipality. It were
\end{abstract}

Palavras-chave

Mobilidade urbana Tráfego urbano Análise de tráfego urbano

Palabras clave

Movilidad urbana Tráfico urbano Análisis del tráfico urbano

\section{Keywords}

Urban mobility Urban traffic Analysis of urban traffic 
analyzed the hourly flow variation throughout the day at the analyzed points, daily variation considering weekdays and seasonal, along the months and the influence of weekends and holidays in the flow of vehicles. The results of the evaluations allowed to identify the influence of the seasonal patterns in the points of study, to identify peak times and flows, days of greater movement and the influence of weekends and holidays.

\section{Introdução}

O crescimento demográfico e da frota de veículos automotores apresenta-se como um dos principais desafios da atualidade para o planejamento de centros urbanos. As elevadas taxas de motorização, sobretudo em países em desenvolvimento geram diversas externalidades com implicações negativas na saúde pública da população ao meio ambiente (Cohen y Castillo, 2017, Lee et al., 2005), assim como refletem no desenvolvimento socioeconômico do município e do país, principalmente devido a problemas relacionados a congestionamentos, tempo e consumo combustíveis em excesso (ANTP, 1999; Scaringella, 2001; IPEA, 2013; Alzate et al., 2007). Estes fatores contribuem para reduzir a competitividade econômica e a produtividade de trabalhadores gerando um custo social indesejável para a sociedade (Resende y Souza, 2009; Camagni et al. 2002).

No Brasil, este fenômeno é recorrente, sendo um problema que não é mais restrito a grandes centros urbanos, estando presente em municípios de portes variados, sobretudo em regiões metropolitanas ou em arranjos populacionais (contiguidade das manchas urbanizadas e fortes relações de fluxo de pessoas e mercadorias entre si (IBGE, 2016a). Gebeyehu y Takano (2007) e Rubin y Leitão (2013) alertam que as elevadas taxas de motorização em países em desenvolvimento decorrem de um transporte urbano de baixa eficiência, poucos investimentos em infraestrutura ferroviária e a adoção de modelo urbano que prioriza espaços públicos para a circulação de carros. Segundo Resende y Souza (2009) quanto maior a renda da população, maior o desejo das pessoas de usar o transporte individual, como aponta a Pesquisa Mobilidade da População Urbana de 2017 (NTU, 2017). Assim, muitas pessoas preferem viajar sozinhas por causa do conforto, da privacidade, flexibilidade e rapidez, diferentemente do que elas experimentariam se usassem o transporte público.

O gerenciamento e mediação destes conflitos depende, de forma imprescindível, de uma gestão da informação, que por vezes não ocorre adequadamente. Problemas de ordem institucional que contribuem para o agravo destes problemas, como a precariedade de procedimentos de geração de dados técnicos de parâmetros do trânsito, a ausência de rede de monitoramento de fluxos, contagem de veículos e de sistema de informação aplicado a gestão de estratégica de tráfego. Khreis et al. (2016) ressalta que o planejamento urbano desconexo planejamento em transportes causa prejuízos à eficiência da mobilidade urbana.

Isso compromete ainda, o desenvolvimento de pesquisas técnicas e científicas, o que inviabiliza a realização de estudos de eficiência e viabilidade de ações ou diferentes abordagens de transportes. E dessa forma, um modelo ineficiente de mobilidade passa a ter seu uso recorrente e por vezes replicado, criando um ciclo vicioso que potencializa todos os impactos negativos supracitados.

Nesse sentido, o objetivo da pesquisa é o de determinar os padrões sazonais de deslocamento viário tendo por estudo de caso, dados de tráfego no município de Balneário Camboriú, Brasil. O trabalho visa ainda determinar a variação horária ao longo do dia dos fluxos nos pontos analisados, variação diária considerando dias úteis e sazonalidade ao longo dos meses com dados disponíveis e a influência dos finais de semana 
e feriados no fluxo de veículos nos pontos analisados, além de estabelecer correlação com a dinâmica demográfica do município, visando a identificação de ações para a melhoria da mobilidade urbana.

Ademais, o estudo visa analisar a influência de fluxos populacionais decorrente de atividades de turismo no município, sendo um fator determinante para muitas cidades para um pleno planejamento urbano, uma vez que, a população flutuante atua de forma contundente nas relações socioeconômico, ambiental e espaciais no contexto urbano. Gomes (2010) enfatiza que o trânsito se tornou fator de maior importância nos conceitos atuais de cidades, podendo por si só, atrair ou não pessoas e capital para certas áreas promovendo o desenvolvimento ou a estagnação destas.

Dessa forma, cidades turísticas possuem uma circulação maior de pessoas e mercadorias, o que demanda um planejamento mais apurado do sistema de transportes e trânsito, visando compatibilizar o turismo com as demais atividades da cidade. Mesmo assim, problemas com congestionamentos e dificuldade de locomoção representam uma das principais incomodidades urbanas, e problemas crônicos podem afligir inclusive, as atividades turistas. Em tal cenário, visitantes não teriam as suas expectativas satisfeitas, o retorno financeiro seria minimizado, comunidades urbanas se oporiam ao crescimento das atividades turísticas e o próprio patrimônio turístico pode ser ameaçado (Gomes, 2010).

Liu y Sharma (2006) atentam para a existência de variações significativas do volume de tráfego durante os períodos de férias, sendo que os seus efeitos podem ocorrer não apenas nos feriados, mas abrangem períodos mais longos, incluindo os dias adjacentes a estes períodos, podendo causar sérios problemas no planejamento e operações rodoviárias Dessa forma, uma caracterização do tráfego, considerando os efeitos de períodos de férias e feriados pode ajudar a desenvolver contramedidas práticas em vários aspectos, tais como planos de controle de tráfego, cronograma de sinalização, programas de segurança, monitoramento de volume de tráfego, imputação e previsão.

\section{Estudos de tráfego}

Smeed (1968) aponta que estudos científicos de tráfego devem ser orientados a produzir uma descrição objetiva e abrangente dos elementos factuais subjacentes aos problemas, e mediar os diferentes interesses de grupos da sociedade acerca das melhores soluções de mobilidade para dada realidade. Nesse sentido, o desenvolvimento de estudos de tráfego é fundamental, representando um modelo da realidade, exprimidos por métodos físicos e matemáticos, inseridos dentro de um determinado campo restrito. Estes permitem a compreensão de alguns dos fatores de que depende a circulação de veículos e pedestres, e dessa forma são desenvolvidos por razões práticas, para que sejam determinadas estratégias efetivas para facilitar a condução de medidas eficazes para facilitar o desenrolar do tráfego e reduzir os seus efeitos nocivos (Smeed, 1968).

A partir de informações de tráfego é possível avaliar a qualidade de serviços das vias, permitindo uma análise sistemática e consistente acerca da capacidade do sistema que envolve a combinação de diferentes modais. Entre os parâmetros passíveis de serem determinados destacam-se o fluxo de saturação, tempos de espera, reserva de capacidade, eficiência da via e cruzamentos, etc. (TRB, 2000).

Smith y Demetsky (1997) afirmam que para o planejamento dos transportes e mobilidade urbana é imprescindível um conhecimento dos fluxos de veículos e características 
de deslocamento, tais como a composição do fluxo, volumes por tempo e distribuição temporal. A capacidade de prever volumes de tráfego tem sido identificada como necessidade crítica para a constituição de sistemas inteligentes de transportes.

Segundo Oliveira (2004) considerando que o volume de tráfego varia significativamente durante o dia, o volume horário em que a demanda atinge o seu máximo é referido como Volume de Hora de Pico (VHp), sendo a medida de maior relevância nas principais medidas de controle e capacidade, como por exemplo nas análises operacionais semafóricas e de nível de serviço, de modo que as facilidades projetadas atendam ao período de pico de tráfego.

Estudos específicos de volume são aplicados para se obter a informação efetiva do movimento de veículos e/ou pessoas de pontos selecionados do sistema viário, e os dados resultantes são expressos em relação a um período de tempo, que é determinado pela aplicação na qual a informação será usada. Devido a limitações de tempo e recursos, tem sido obtida frequentemente por estimativas baseadas em volumes inferiores a um ano, inclusive a partir da expansão de determinados volumes horários, fazendo o uso de fatores de expansão gerados a partir de base histórica de dados Oliveira (2004).

Vasconcellos (2000) aponta os desafios para o planejamento de transportes em países em desenvolvimento, com destaque para dificuldades frente a obter-se dados confiáveis, falta de técnicos treinados, além de problemas políticos e governamentais que dificultam a realização de planejamento estratégico e inclusivo.

A ausência de um sistema de informação consistente acerca de estatísticas de tráfego, contagens de veículos, em subsídio à realização de diagnósticos mais precisos é uma deficiência grave ao planejamento urbano. Estudos de Pepe et al. (2010) e Pontes (2010) apontam para problemas da falta de dados e da qualidade das informações de gerenciamento de tráfego devido principalmente à ausência de uma estrutura adequada para a coleta, tratamento e atualização dos dados.

Destaca-se aqui, iniciativas governamentais referentes ao Plano Nacional de Contagem de Tráfego (PNCT). Implementado de forma gradativa a partir de 1975, as contagens eram realizadas em vias federais por iniciativa da Polícia Federal nos estados de SP, RJ e MG. Posteriormente foi expandido para mais estados, mas atualmente este sistema sofreu modificações, sendo a contagem feita por meio de contratações específicas para determinados pontos de rodovias federais (DNIT, 2016).

Ao mesmo tempo, importantes iniciativas que poderiam ser utilizadas para o monitoramento e integração de dados não são consideradas ou são subutilizadas, como: estudos pontuais de tráfego, estudos de impacto de vizinhança, obtenção de dados por meio de câmeras de monitoramento da segurança pública, radares de monitoramento de velocidade, etc. Comumente, devido à ausência de integração institucional entre os diferentes agentes da gestão pública estas fontes de dados não são sistematizadas, deixando de viabilizar a composição de banco de dados para subsidiar diagnósticos mais robustos e nesse sentido, definir melhor as estratégias de mitigação de danos ambientais, sociais e prejuízos econômicos (Seabra et al., 2013).

\section{Metodologia}

O trabalho consistiu em extrair dados de caracterização do tráfego do município de Balneário Camboriú (SC, Brasil) em pontos de medição específicos por meio de radares de controle eletrônico de velocidade. Após verificação da consistência dos dados, foram calculados os fluxos diários e mensais e sua variação semanal e sazonal entre os meses de agosto a março 
com objetivo de avaliar o comportamento temporal do fluxo diário, semanal e mensal, além de obter indicadores como a hora e fluxos de pico diários, composição do trafego, variação acumulada de meses de maior e menor fluxo (Figura 1). Foram aplicadas análises estatísticas aos dados para identificar variações significativas, realizadas no software Portal Action.

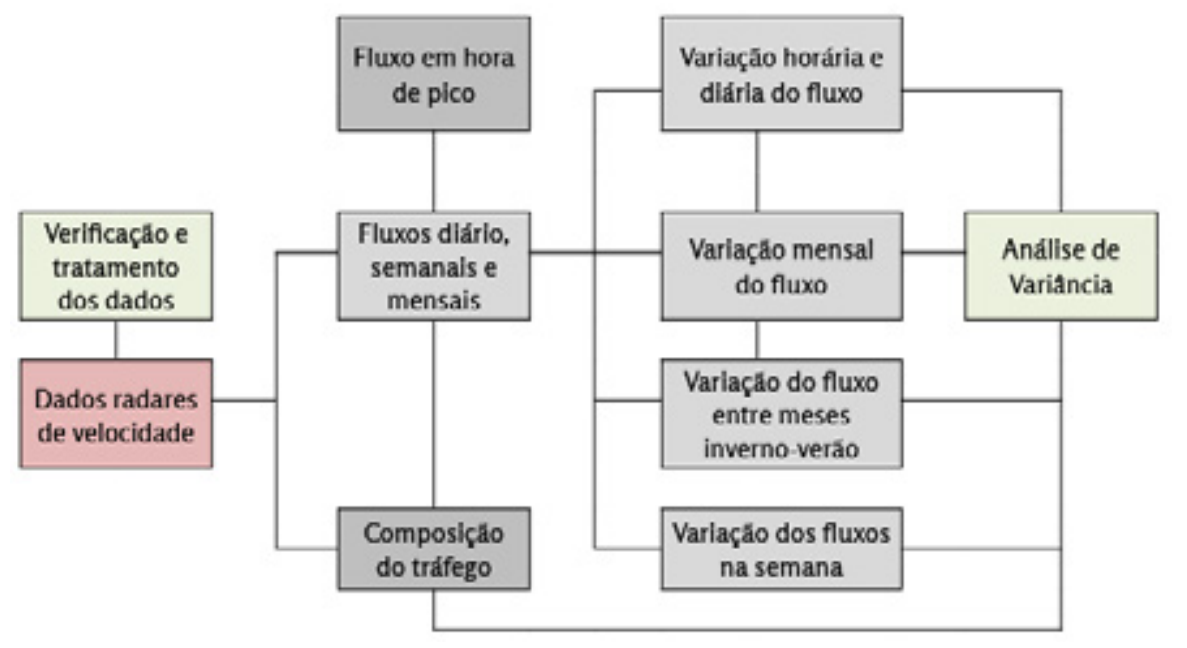

Figura 1. Fluxograma de desenvolvimento da pesquisa. Fonte: O Autor

\section{Estudo de caso}

A pesquisa utilizou como estudo de caso o município de Balneário Camboriú, localizado no litoral Centro-norte de Santa Catarina. A região integra um polo econômico, e representa $\mathrm{o}$ arranjo populacional de médio porte de maior contingente populacional de turismo e veraneio do Brasil (IBGE, 2016, a). Além da grande circulação de pessoas e mercadorias, o município possui um expressivo fluxo turístico ao longo de todo o ano, e diversas questões relacionadas a mobilidade urbana encontram-se em conflito constante. Com isso, a região constitui um dos maiores desafios de mobilidade urbana do estado, e com desafios semelhantes a diversas regiões metropolitanas do país.

Dados do cresciemento demográfico entre 2015/2016 (IBGE, 2016b) demonstram que a região de Balneário Camboriú desponta entre as cidades entre as que mais crescem no Estado, com destaque para Itapema (5,6\%), Navegantes (3,01\%), Camboriú $(2,9 \%)$, Balneário Camboriú (2,79\%), Penha (2,61\%), Brusque (2,47\%) e Itajaí (1,8\%). Ainda, entre 2000-2015 Balneário Camboriú representou a terceira cidade de interior, com mais de 100 mil habitantes que cresceu no país. Fatores estes que contribuem para outro fenômeno denominado de movimento pendular, onde viajantes rotineiros (trabalhadores, estudantes) deslocam-se de seu local de residência para local onde desempenham atividades de forma cíclica, geralmente com picos de trânsito matutinos e vespertinos bem definidos e geralmente entre municípios vizinhos. Segundo o DNIT (2006) nas vias urbanas a predominância das idas e voltas aos locais de trabalho faz com que os picos de volume de tráfego se concentrem nos dias de semana, de segunda a sexta-feira.

Historicamente, o município de Balneário Camboriú tem o turismo como um de seus principais aspectos econômicos e sociais. Segundo dados da Prefeitura Municipal o município recebe mais de 3 milhões de turistas anualmente, atingindo a picos de cerca de 700 mil turistas no mês de Janeiro (PMBC, 2017) (Figura 2). É interessante destacar que mesmo em meses de inverno, há um fluxo expressivo de turistas. No mês de junho, geralmente mês de menor população flutuante, observam-se cerca de 200 mil turistas mensal, superior a população de residência permanente de 138.732 habitantes (IBGE, 2018). 


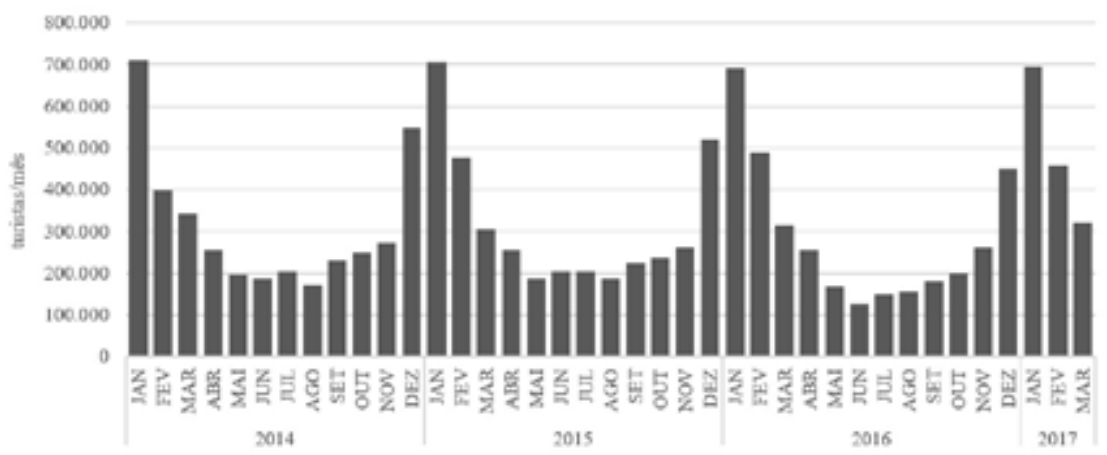

Figura 2. População flutuante no município de Balneário Camboriú (turistas por mês). Fonte: Dados PMBC, 2017.

O município movimenta fluxo expressivo de turistas regionais, dos quais muitos possuem segunda residência no município, utilizada ocasionalmente, além dos meses de veraneio, geralmente em finais de semana, independentemente da época, porém mais intenso no verão (Tischer, 2014). O entendimento desta dinâmica demográfica é fundamental para avaliar o sistema de transportes e subsidiar ações estratégicas de planejamento e mobilidade urbana.

\section{Base e tratamento de dados}

A base de dados analisada foi obtida de radares de controle de velocidade gerenciado pela Prefeitura Municipal de Balneário Camboriú, especificamente pelo Fundo Municipal de Transito (FUMTRAN). Os radares estão instalados em 25 pontos do município, sendo diferenciados em acordo com o objetivo do equipamento: radar fixo, avanço de sinal, avanço de sinal não intrusivo e lombada eletrônica. Entretanto, apenas este último é passível de utilização devido a ser o único equipamento a registrar todos os veículos que passaram pelo ponto, estando seis pontos disponíveis (Quadro 1).

Quadro 1. Descrição dos pontos de monitoramento estudados. Fonte: O Autor.

\begin{tabular}{|c|c|c|c|c|c|}
\hline Ponto & Faixa & Direção & Sentido & Rua / Av. / Rod. & Bairro \\
\hline \multirow{2}{*}{$\mathrm{P}_{1}$} & 1 & \multirow{2}{*}{$D_{1}$} & Baln. Camboriú - Itajaí & \multirow{2}{*}{ Avenida do Estado, 371} & \multirow{4}{*}{ Ariribá } \\
\hline & 2 & & Baln. Camboriú - Itajaí & & \\
\hline \multirow{2}{*}{$\mathrm{P}_{1}$} & 3 & \multirow{2}{*}{ D2 } & Itajaí - Baln. Camboriú & \multirow{2}{*}{ Avenida do Estado, 476} & \\
\hline & 4 & & Itajaí - Baln. Camboriú & & \\
\hline \multirow{2}{*}{$\mathrm{P}_{2}$} & 1 & $\mathrm{D}_{1}$ & Leste-Oeste & \multirow{2}{*}{$\begin{array}{l}\text { Rua Dom Afonso, esq. Rua } \\
\text { Dom Bruno }\end{array}$} & \multirow{2}{*}{ Vila Real } \\
\hline & 2 & D2 & Oeste - Leste & & \\
\hline \multirow{2}{*}{$P_{3}$} & 1 & $D_{1}$ & Sul - Norte & \multirow{2}{*}{ Rua Antonio Bittencourt, 200} & \multirow{2}{*}{ Pioneiros } \\
\hline & 2 & D2 & Norte - Sul & & \\
\hline \multirow{2}{*}{$\mathrm{P}_{4}$} & 1 & \multirow{2}{*}{$D_{1}$} & Centro - Bairro & \multirow{2}{*}{ Rua 1500,1058} & \multirow{2}{*}{ Centro } \\
\hline & 2 & & Centro - Bairro & & \\
\hline \multirow{2}{*}{ P5 } & 1 & \multirow{2}{*}{$\mathrm{D}_{1}$} & Centro - Barra Sul & \multirow{2}{*}{ Avenida Brasil, 3480} & \multirow{2}{*}{ Centro } \\
\hline & 2 & & Centro - Barra Sul & & \\
\hline \multirow{2}{*}{ P6 } & 1 & $D_{1}$ & Itapema/Estaleirinho & \multirow{2}{*}{ L.A.P. Rodesindo Pavan } & \multirow{2}{*}{ Estaleirinho } \\
\hline & 2 & D2 & Estaleirinho/Itapema & & \\
\hline
\end{tabular}

Estes pontos encontram-se bem distribuídos ao longo do território (Figura 3). No mapa foi caracterizado ainda, os Bairros do município que recebem a maior influência do turismo (Bairros Praia dos Amores, Pioneiros, Centro e Região das Praias) assim como demarcado de forma ilustrativa, a área central onde o fluxo de pessoas e carros é intensificado por conta da concentração do turismo. 


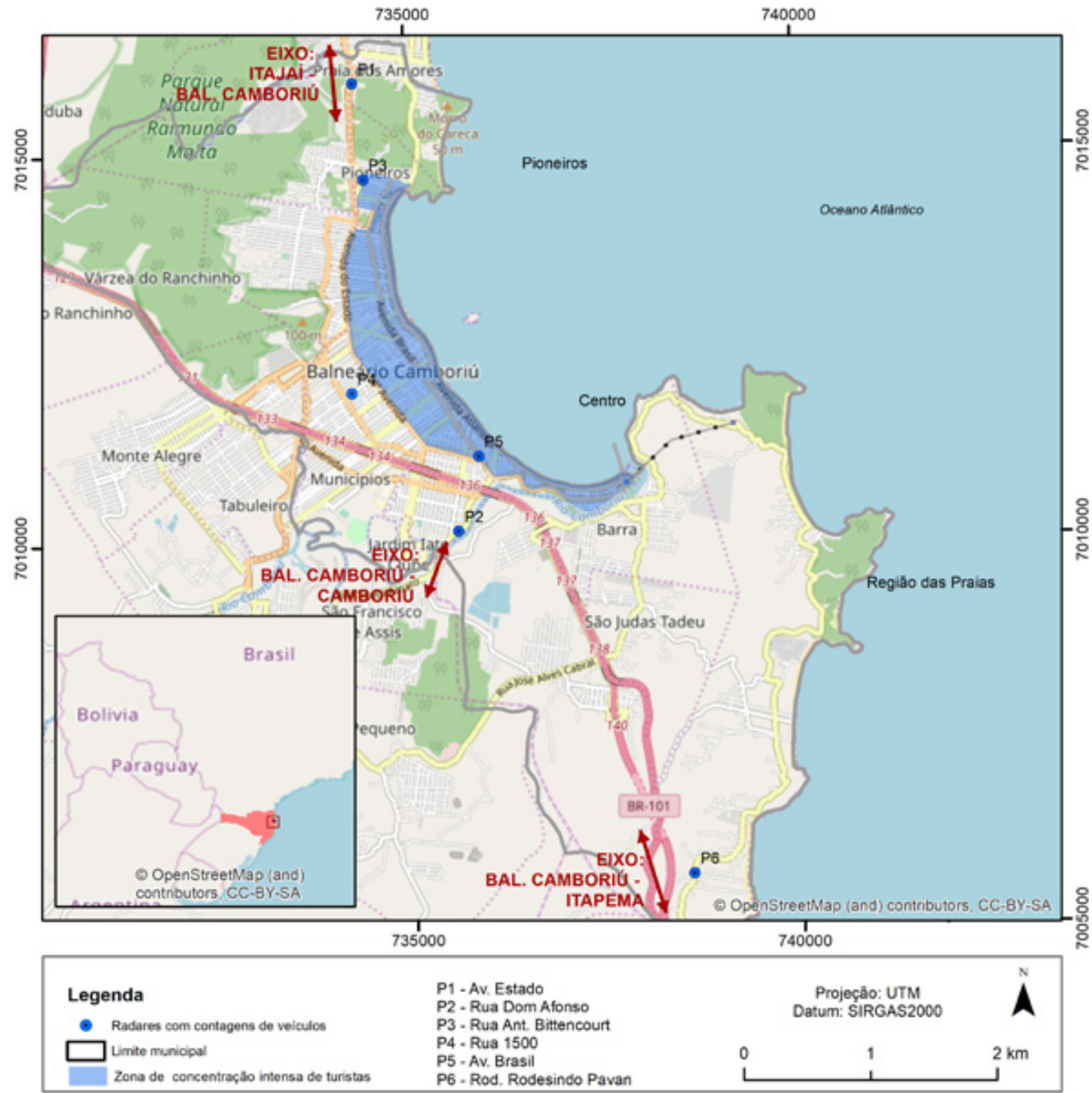

Figura 3. Localização dos pontos de contagem e áreas de fluxo sazonal de turismo no município de Balneário Camboriú e eixos de conexão intermunicipal. Fonte: $O$ Autor.

A base de dados bruta em sistema .sql foi exportada para formato xls permitindo o tratamento e seleção de dados de interesse. O radar registra o momento da passagem do veículo pelo sensor, estando disponíveis o horário e data de passagem, velocidade, faixa, tipo de veículo e largura. Os dados de volume de veículos foram agrupados em intervalos de 15 minutos, por faixa e tipo de veículo para obter-se a composição do fluxo, sendo classificados em carros, motocicletas, caminhões e ônibus.

Após agrupamento dos dados de interesse esses foram verificados para eliminar valores outliars. Em radares de monitoramento apesar do contínuo monitoramento dos veículos, é comum lacunas de valores, sejam por motivos de manutenção, ou falhas na contagem, e dessa forma alguns dias não são passíveis de serem utilizados. Nesta análise foram observadas que cerca de $4 \%$ dos dados estão ausentes ou com valores não compatíveis com os demais, não sendo considerados para a análise. 


\section{Fluxos horários}

As análises diárias foram desempenhadas considerando as somatórias dos fluxos, em intervalos de 15 minutos, nos pontos analisados, e em cada direção para os pontos com vias de sentido duplo. Isso é importante para que sejam verificados efeitos de fluxo pendulares, haja visto que algumas vias são importantes eixos de conexão com municípios vizinhos, permitindo compreender melhor este processo. Ressalta-se que esta análise é desempenhada por meio de amostragem, utilizando um número definido de datas avaliadas devido as limitações operacionais de recuperação dos dados ordenados por intervalos de 15 minutos. As demais análises, no entanto, consideram o universo dos dados obtidos.

Foram consideradas pelo menos duas datas diferentes por mês, para cada ponto e direção, com objetivo de verificar possíveis diferenças nos fluxos ao longo dos dias úteis da semana, dentro do mesmo mês. Não foram utilizados dados de sextas-feiras, além de dias de vésperas e pós-feriado para que não exerçam influência durante as comparações das variâncias das médias, haja visto crescimento de fluxo nestas datas como demonstrado por Liu y Sharma (2006).

Por meio dos valores da variação dos fluxos diário foi possível determinar a hora de pico e o seu fluxo relacionado. Esta medida é importante para o planejamento urbano, permitindo conhecer a efetividade da capacidade da via, horário com os fluxos mais críticos e subsidiar medidas de controle de tráfego ou estratégias de redução de congestionamentos. Uma vez compilados os fluxos diários para todos os meses com dados disponíveis, a porcentagem relacionada ao volume na hora de pico foi obtida por meio da média dos fluxos nas horas de pico dos meses em análise.

\section{Variação semanal do fluxo diário}

Dias úteis

Para a avaliação da variação semanal dos dias úteis, os volumes diários foram somados por dia da semana (exclusive feriados), aos quais foi aplicado teste estatístico de comparação entre variâncias dos grupos, sendo utilizado o teste Fisher (Teste-F) para verificar diferenças significativas entre dos fluxos diários na semana. Desta forma, foram possíveis realizar comparação entre todos os grupos existentes (de segunda a sexta-feira. Os dados apresentaram normalidade (teste Kolmogorov - Smirnov p =0,198, com intervalo de confiança de 95\%).

Outra simulação considerou como variáveis dependente agrupamentos por mês, visando identificar a variação sazonal ao longo dos meses (Teste F) e avaliados segundo a participação relativa de cada dia da semana para a composição do fluxo nos dias úteis, sendo possível verificar os volumes médios relativos para cada dia útil da semana.

A partir desta análise foi desenvolvido balanço dos fluxos entre o mês de menor fluxo com o mês de maior fluxo visando obter valor médio, em porcentagem, da variação do fluxo nestes meses, permitindo identificar prontamente a existência de variação entre mês de inverno e mês de verão.

\section{Fim de semana e feriados}

Para esta avaliação os dados foram triados para obter-se apenas os dias não-úteis, sábados, domingos e feriados. Estes foram agrupados considerando o volume de tráfego diário registrado pelo radar para que permitisse realizar tratativas estatísticas e determinar a variância das médias entre os meses do registro de dados (Teste F). 
Quatro dos seis pontos analisados são vias que possuem fluxos em ambos os sentidos, e com isso há uma variação natural de fluxos entre os sentidos. No entanto, as análises das variações sazonais para dias-não úteis foram realizadas por ponto, considerando o somatório total por ponto, não sendo o objetivo avaliar diferenças entre as direções nesta ponderação.

\section{Composição do tráfego}

A composição do trafego foi realizada tendo como base a média mensal dos fluxos diários, por tipo de veículos e por ponto de análise. Foram considerados os mesmos dados utilizados para os fluxos horários. Como resultados, foram desenvolvidos gráficos de composição do fluxo por ponto considerando as médias mensais, além de ser realizada comparação da variância dos dados entre os meses por meio do Teste-F para verificar se há mudanças significativas na composição dos veículos entre os meses avaliados.

\section{Resultados}

\section{Variação horária dos fluxos diários}

Os resultados obtidos foram apresentados na forma de gráficos para expressar o perfil do desenvolvimento do volume horário de veículos ao longo do dia. Esta representação possibilita identificar períodos de maior fluxo, picos da manhã, tarde, meio dia e, ao mesmo tempo, compará-los com a variação sazonal, por meio dos valores dos outros meses de monitoramento.

O ponto P1, representa a Avenida do Estado, sendo uma das principais vias estruturantes da paisagem urbana do município. Esta possui os maiores volumes nos pontos analisados, possibilitado também por realizar conexão intermunicipal com os municípios de Camboriú e Itajaí (como é o caso do P1). A direção D1 refere-se ao fluxo Balneário Camboriú-Itajaí, e direção D2, fluxo no sentido contrário.

O horário de pico identificado para a direção D1 é no período matutino, entre 7:15 às $8: 15 \mathrm{~h}$ e a D2 pela tarde, entre as 17:30 às 18:30h, com fluxos de pico na ordem de 1.800 veículos/dia. Neste ponto ficou caracterizado por padrão de movimento devido a rotinas estabelecidas (Figura 4). A direção 1, refere-se ao fluxo Balneário Camboriú-Itajaí, a qual tem por fluxo de pico o horário da manhã, indicando um fluxo relevante de pessoas que trabalham/estudam em Itajaí e residem em Balneário Camboriú. Na direção oposta, em contrapartida, o fluxo de pico acontece no final da tarde, o que caracteriza o retorno deste contingente de Itajaí para Balneário Camboriú.

As duas cidades possuem forte relações de deslocamento de pessoas e mercadorias, ficando evidente que a via representa o principal corretor intermunicipal entre as duas cidades, sendo uma via chave para intervenções de mobilidade urbana, principalmente no que tange o transporte coletivo. Um sistema efetivo poderia reduzir significantemente o impacto expressivo no trânsito causado por veículos individuais. Como demonstra a foto apresentada pela Figura 4, a via possui características de rodovia, com duas faixas independentes em cada um dos sentidos, gerando fluxos de trânsito rápido, apesar do limite de velocidade ser $50 \mathrm{~km} / \mathrm{h}$. A via carece de infraestrutura adequada para pedestres e ciclistas, gerando ponto de risco à circulação destes.

Com relação ao ponto 2, na Rua Dom Afonso observa-se que os pico de tráfego encontram-se na faixa de 700 veículos/hora em ambos os sentidos (Figura 4). No entanto, na D1 (fluxo de leste para oeste) a hora de pico é entre as 17:30 às 18:30h, e para a 
direção contraria (oeste-leste) o pico é observado pela manhã entre as 7:15 e 8:15h, sendo identificado um deslocamento pendular bem marcado. Pela manhã a maioria dos deslocamentos se dá no sentido Camboriú-Balneário Camboriú, e pela tarde os maiores fluxos se dão no sentido contrário, onde os trabalhadores retornam para a sua casa, no fim da tarde.

Tal como no ponto 1, esta via representa importante eixo pendular entre as cidades de Camboriú e Balneário Camboriú, caracterizados principalmente pelas relações de trabalho, que demonstram Camboriú com características de cidade-dormitório, sendo outro eixo fundamental para o transporte público, sendo que não há efetividade de transporte público neste eixo, além da carência de infraestrutura cicloviária que impõe riscos a ciclistas. No geral, apesar do alto fluxo por faixa, o trânsito flui bem, havendo, no entanto, dois pontos nodais de conflito consistindo em interseções da via com Avenida Quinta (em destaque na Figura 4) e com a Rua Dom Felipe, porção sul da via. Como não há faixa de espera para conversões, estes movimentos geram barramento do fluxo em horários específicos do pico da tarde, coincidindo com o final do expediente de trabalho e inicio de aula em universidade próxima a região, expressivo polo gerador de tráfego.

Destaca-se aqui a conurbanção de Balneário Camboriú com Camboriú e Itajaí, formando um aglomerado urbano de intensas trocas de pessoas e mercadorias, como demonstraram os dados de fluxo. Associado a isso, ao fato de Balneário Camboriú possuir a maior densidade demográfica do Estado. Isso faz com que a localidade tenha um potencial para a implementação de transporte coletivo viável, atrativo e eficiente aumentando a eficiência e produtividade da cidade evitando as consequências negativas de cidades espalhadas e de baixa densidade ressaltadas por Banister (2015) e Figueroa (2005). Além disso, Edwing y Cervero (2017) destaca que cidades compactas proporcionam que pessoas dirijam menos, compatibilizando uma das vocações do município, além de ser uma cidade com topografia plana.

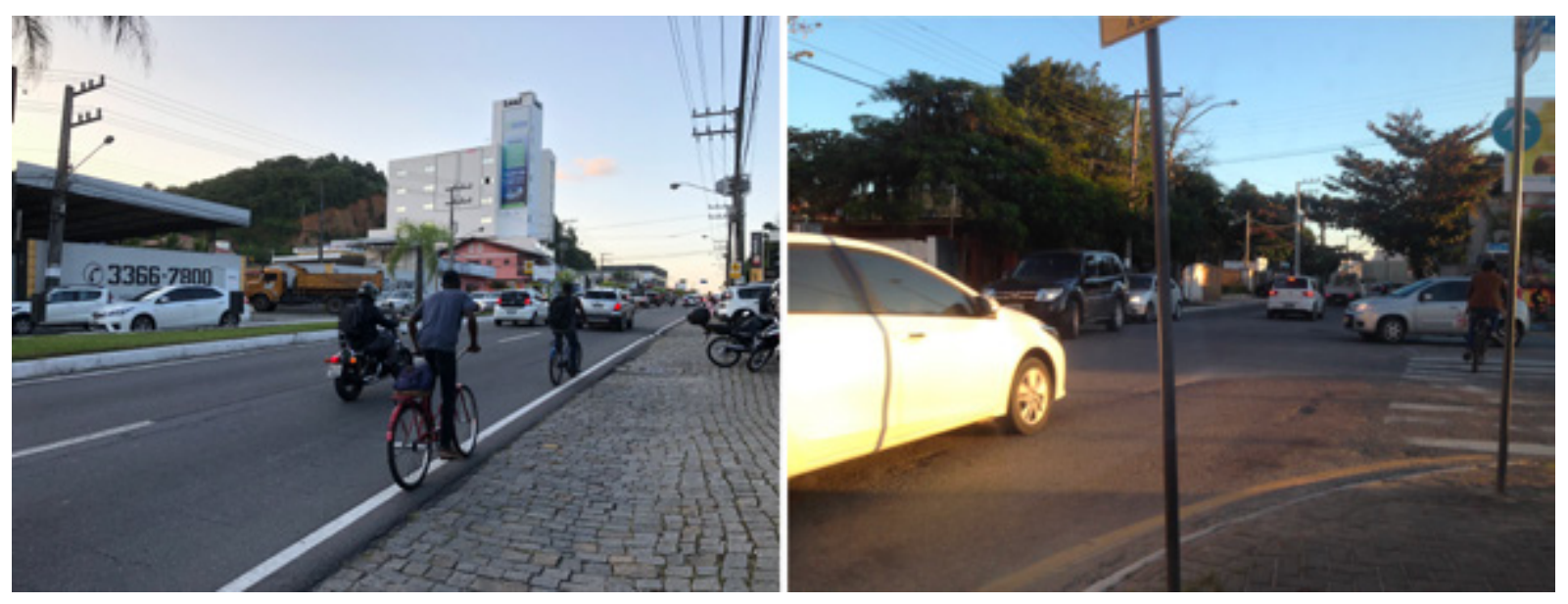

Figura 4. Trecho da Avenida do Estado ( $\left.P_{1}\right)$ (esquerda) da Rua Dom Afonso (direita) $\left(P_{2}\right)$ em Balneário Camboriú. Fonte: $O$ Autor.

No ponto P3 observa-se um fluxo maior de veículos no sentido sul-norte no sentido de acesso à Rua Miguel Matte, com um fluxo pico de cerca de 400 veículos por hora, no final da tarde entre as 18:00-19:00h. Na direção contrária, D2, o fluxo é menor. No horário de pico entre 17:00-18:00h o fluxo encontra-se na ordem de 300 veículos/hora. Esta via insere-se paralelamente entre duas vias arteriais (Av. Brasil e Estado) e distribui os fluxos para as vias locais do Bairro Pioneiros. Mesmo sendo uma via de pequena extensão, desenvolve um papel de importante conectividade, fornecendo rápido acesso a áreas adjacentes, além de ser muito utilizada por ciclistas e pedestres (Figura 5). 
No ponto P4 (Rua 1500) se observam dois horários de pico, variando de acordo com a época do ano, com os maiores volumes identificados no início da tarde das 13:00-14:00h e no final da tarde, das 17:15-18:15h atingindo fluxos na ordem de 1000 veículos/hora. Este ponto é importante eixo de ligação entre o centro urbano mais denso da cidade à sua área marginal, dando acesso a rodovia intermunicipal (BR-101) para outros municípios da região, além de acesso a eixos viários para região norte ou sul da cidade. O fluxo principal ocorre à tarde com o deslocamento de trabalhadores do centro da cidade para regiões periféricas da cidade. Também é importante rota para o transporte público e ciclistas, apesar das faixas serem compartilhada entre todos os modos.
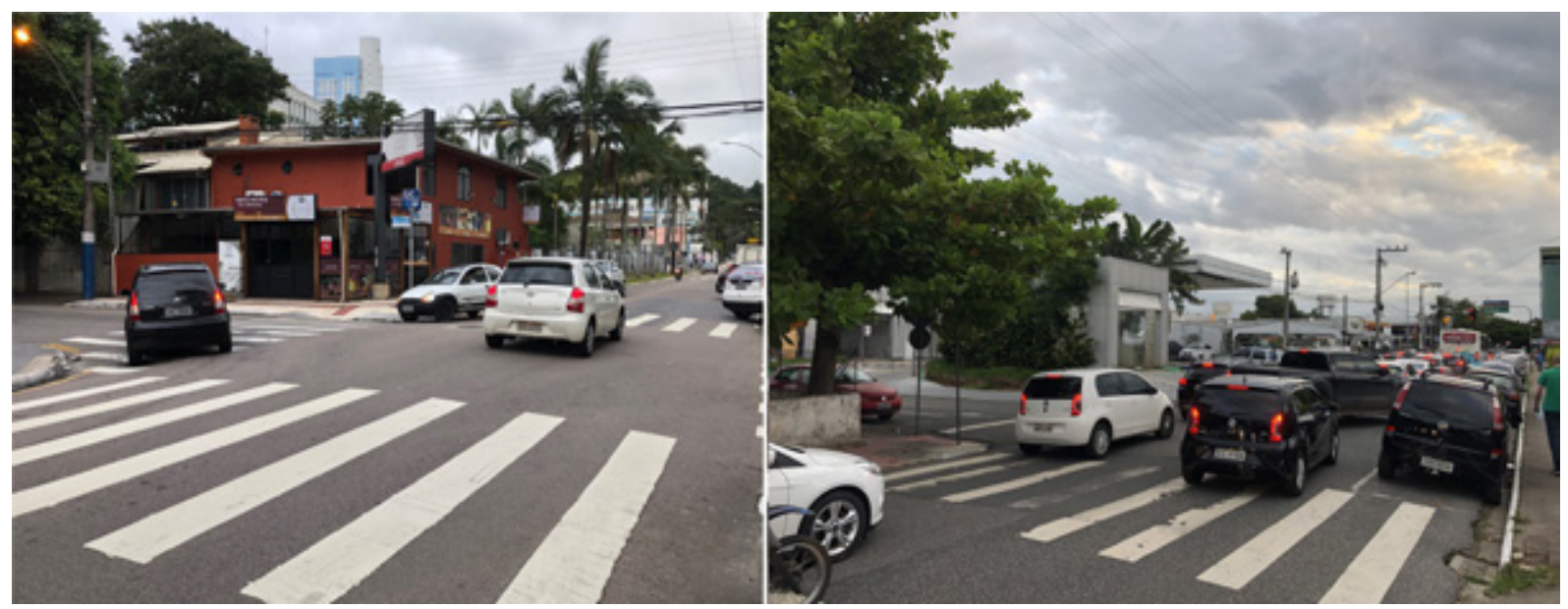

Figura 5. Trecho da Rua Antônio Bittencourt $\left(\mathrm{P}_{3}\right)$ (esquerda) e Rua $1500\left(\mathrm{P}_{4}\right)$ (direita). Fonte: $O$ autor.

O Ponto P5, referente a Av. Brasil, possui um fluxo na hora pico das 17:30-18:30h na ordem de 800 veículos/hora. Esta avenida além de representar uma via arterial que perpassa o município de norte a sul, é uma das principais afetadas pelo trânsito urbano no município, em especial durante fins de semana, feriados e período de veraneio. Em diversas ocasiões verifica-se que o fluxo mensurado fica abaixo da média de vias de hierarquia similar, devido a presença de congestionamentos, desenvolvendo menos o fluxo e, dessa forma, refletindo na contagem.

A via representa um dos eixos chave da mobilidade no município, porém atualmente, os problemas gerados de trânsito representam grande desafio, que passam pela necessidade de redução da dependência de carros, da limitação física da seção transversal com perfil altamente denso. Observa-se na Figura 7 a presença de ciclofaixa que contribui a melhoria da circulação de ciclistas, no entanto ainda gera risco a ciclistas devido ao elevado densidade de interseções junto a Avenida Brasil, além da demanda por melhorias de segurança e sinalização.

Com relação ao ponto P6, localizado na Rodovia Rodesino Pavan, bairro afastado do centro do município, observa-se uma dinâmica diferenciada, com crescimento do fluxo exponencialmente no período de alta temporada. A direção D1, sentido Itapema-Balneário Camboriú possui menor fluxo, na ordem 100 veículos/hora. O horário de pico, apesar de variações imposta pela sazonalidade, pode ser inferido entre 18-19 horas. $\mathrm{Na}$ direção oposta (D2) observa-se uma variação maior nos meses de veraneio, com destaque para janeiro, com elevado fluxo comparado com outros meses. No restante dos meses, no entanto, o fluxo mantém-se na ordem de 100 veículos/hora.

Este ponto situa-se em área afastada do núcleo urbano municipal, possuindo uma dinâmica diferenciada da região central do município. Enquanto a região central do 
município, devido a elevada densidade demográfica e de emprego possui fluxos elevados de tráfego e por sua vez, elevadas concentrações de tráfego, a Região das Praias (ponto 6) consiste em uso predominantemente de veraneio, com padrão de ocupação de baixa densidade demográfica, explicando estas diferenças abruptas entre os meses comparativamente aos demais pontos, onde o fluxo é intenso ao longo de todos os meses do anos.
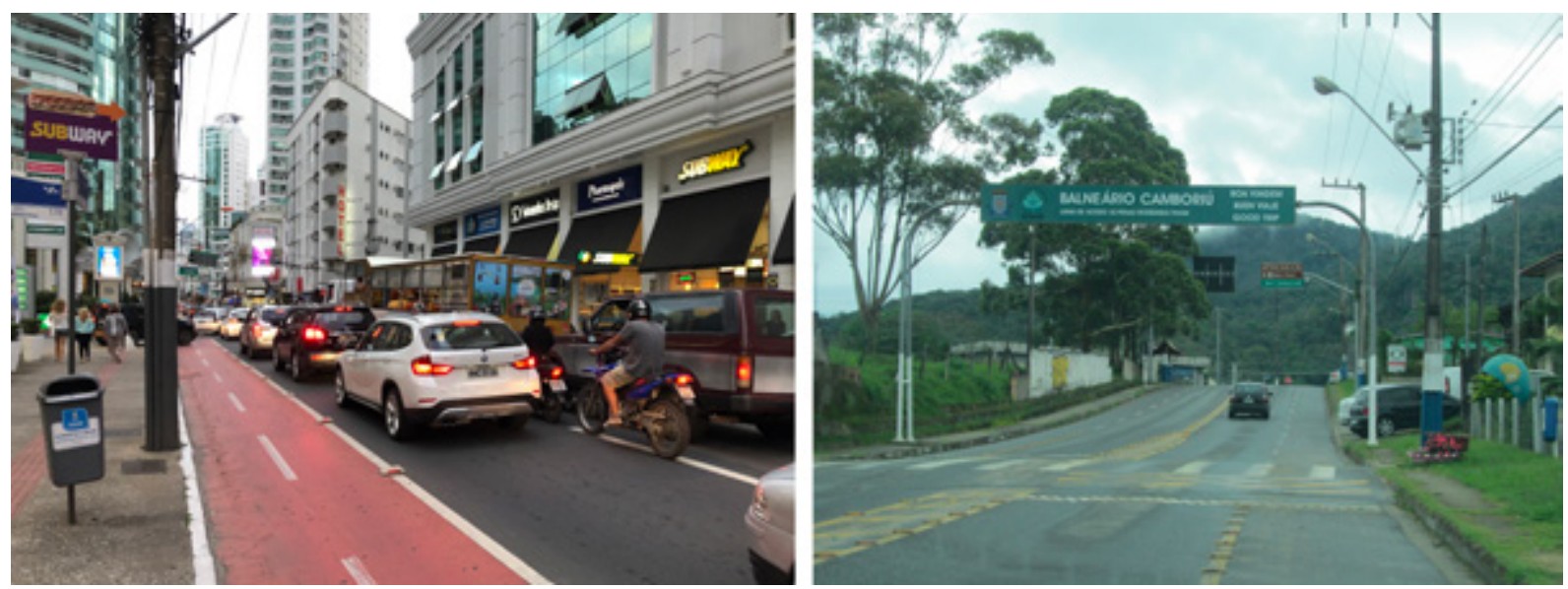

Figura 6. Trecho da Avenida Terceira em Balneário Camboriú próximo ao P5 (esquerda) e Rodovia Rodesindo Pavan (P6) (direita). Fonte: $O$ autor. 

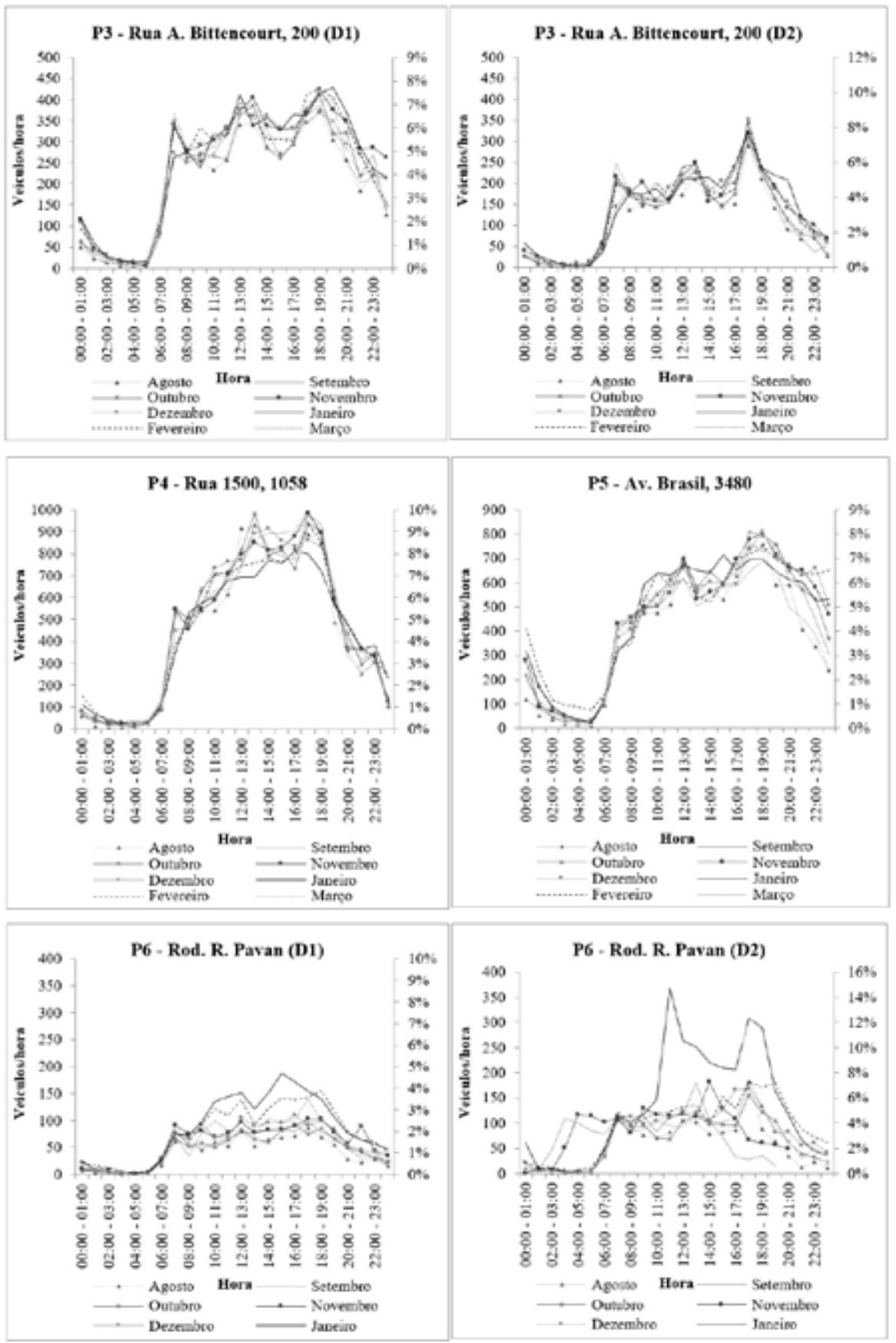

Figura 7. Variação diária nos pontos estudados em dias úteis. Fonte: $O$ Autor.

Apesar de haver um leve aumento no volume de veículos nos meses de verão, observa-se que apenas o ponto 6 indicou a necessidade de rejeitada hipótese de igualdade das variações entre os meses avaliados (Quadro 2), sendo que os volumes não são estatisticamente iguais para os meses de outubro e março. Nesse sentido é importante que as conclusões de variação sazonal sejam feitas considerando a totalidade dos dados. Análise esta, a ser abordada no tópico posterior, permite comparar os fluxos entre os meses por meio de dados do universo coletado pelos radares. 
Quadro 2. Análise de variância entre as amostras replicadas dos mesmos meses (Teste-F). Fonte: O Autor.

\begin{tabular}{|l|c|c|c|c|c|c|}
\hline Mês & $\mathbf{P 1}_{\mathbf{1}}$ & $\mathbf{P 2}_{\mathbf{2}}$ & $\mathbf{P 3}_{\mathbf{3}}$ & $\mathbf{P 4}_{\mathbf{4}}$ & $\mathbf{P 5}$ & $\mathbf{P 6}$ \\
\hline Agosto & 0,891 & 0,971 & 0,964 & 0,599 & 0,403 & 0,269 \\
\hline Setembro & 0,682 & 0,775 & 0,974 & 0,694 & 0,952 & 0,997 \\
\hline Outubro & 0,851 & 0,549 & 0,802 & 0,788 & 0,859 & 0,011 \\
\hline Novembro & 0,665 & 0,584 & 0,814 & 0,482 & 0,511 & 0,441 \\
\hline Dezembro & 0,177 & 0,427 & 0,442 & 0,829 & 0,629 & 0,815 \\
\hline Janeiro & 0,673 & 0,963 & 0,624 & 0,576 & 0,988 & 0,471 \\
\hline Fevereiro & 0,775 & 0,988 & 0,934 & 0,634 & 0,718 & 0,305 \\
\hline Março & 0,472 & 0,974 & 0,833 & 0,597 & 0,760 & 0,029 \\
\hline
\end{tabular}

Um indicador muito útil é o fluxo e na hora pico e a participação relativa deste ao longo do dia. $\mathrm{Na}$ ausência de dados, usualmente adota-se que neste horário, o fluxo corresponde a cerca de um décimo dos volumes diários de veículos em dias úteis. Para o presente estudo de caso, as médias ao longo dos meses, considerando aproximam-se desta convenção, onde a média de todos os pontos foi de 10,3\% (Figura 8).

No entanto, observam-se, variações entre os pontos, e entre as direções, mostrando uma maior discrepância principalmente entre os pontos 2 e 6 . Nestes as direções (D2) concentram mais de $14 \%$ do fluxo nas horas de pico, mostrando uma influência mais proeminente do retorno do expediente de trabalho (ponto 2) e, possivelmente, pelo retorno dos visitantes a partir do final da tarde para o ponto 2, haja visto que este ponto é o que apresenta a maior variação sazonal e função da predominância de atividades de turismo nesta região do município. Com relação aos demais pontos os volumes no horário de pico ficaram entre 8-10\% nos pontos 1, 4 e 5, e o ponto 3 apresentou variação entre $7,2 \%$ (D1) e 10,8\% (D2).

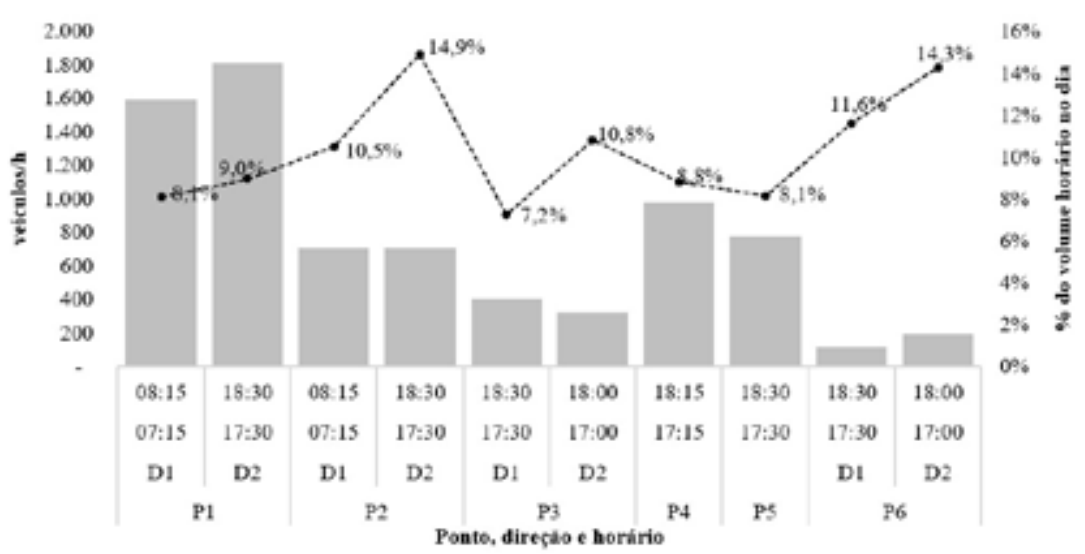

Figura 8. Participação relativa do volume de veículos no horário de pico por direção e ponto analisado. Fonte: O Autor.

\section{Variação semanal do fluxo diário}

Os resultados foram separados em dia útil e fins de semana e feriados, sendo que para o primeiro foram realizadas duas análises, uma considerando os volumes de tráfego para cada uma das direções em dias úteis, verificando a variância entre os dias da semana e outra verificando a variação dos fluxos nos dias úteis ao longo dos meses. Para os fluxos dos fins de semana e feriados foram avaliadas as médias dos fluxos diários ao longo dos meses verificando-se a existência de diferenças significativas entre estes. 


\section{Dias úteis}

Com relação às variações diárias (dias úteis), observa-se que a sexta-feira possui uma diferença significativa dos demais dias, apresentando fluxos superiores (Figura 9). Apesar de geralmente as sextas-feiras possuírem volumes ligeiramente superiores, e segundas-feiras ligeiramente menores do que os demais dias úteis da semana (DNIT, 2006), em Balneário este fenômeno é intensificado, observando-se aumento no fluxo de veículos com a proximidade de fins de semana. Durante os sábados, domingos e feriados o fluxo de visitantes é intensificado, independentemente de fatores sazonais (apesar de no verão ter um volume maior) e com isso, as sextas-feiras correspondem ao período onde estes fluxos começam a elevar-se, e, no geral, possuir volumes maiores de tráfego do que outros dias úteis, fenômeno também identificado por Liu y Sharma (2006). Também foi observada diferença da segunda-feira, para a quinta-feira, esta, porém, menos expressiva e menos frequente.

Essas variações decorrem devido a dinâmica demográfica e cultural do município, sendo local de atratividade de turismo, além de praia e sol, gastronômico, lazer e de compras. Soma-se a isso a presença cultural de fluxos populacionais de curta permanência (fins de semana) de moradores da região que possuem secundas residências no município, garantindo um dinamismo constante do tráfego no município, incluindo feriados, fins de semana e vésperas destes dias. Esse fenômeno faz com que a gestão da mobilidade no município se de forma variada de municípios não turísticos, gerando implicações no controle, fiscalização e segurança de tráfego, além de gerar demanda por infraestrutura de transportes ativos mais expressiva, devido ao elevado número de pedestres e ciclistas.

Com relação a variações entre os meses, observa-se que o mês de agosto registrou diferença significativa de todos os outros meses, podendo ser justificado devida a baixa influência de deslocamentos de turismo por representar mês de inverno. $\mathrm{O}$ mês de Novembro apresenta variações significativas com os meses de Setembro, Outubro, Janeiro, Fevereiro.

No ponto P2 as maiores diferenças ocorrem entre as sextas-feiras e os outros dias da semana. No entanto, destacam-se também as diferenças entre a segunda feira com quarta e quintas-feiras. Com relação a variação entre os meses, destacam-se as variações do mês de agosto com os meses de novembro, dezembro e janeiro, além das variações dos meses de novembro e dezembro com os demais meses.

As variações diárias no Ponto P3 também apontaram a sexta feira com volumes significativamente maiores do que os outros dias da semana. Com relação a variação entre meses para o ponto P3, observou-se uma estratificação mais definida, compatível com a variação sazonal do turismo na região. $\mathrm{O}$ mês de Agosto apresentou diferença significativa de todos os outros avaliados, devido aos menores volumes de tráfego. Os meses intertemporada (setembro a dezembro) apresentaram diferenças significativa com os meses de maior fluxo (janeiro, fevereiro).

No ponto P4, as terças e sextas feira apresentaram diferença significativa das variâncias de volumes entre si e com os demais dias (com exceção da quinta e sexta-feira que podem ser consideradas iguais. A quarta-feira apresentou diferença com a quinta feira. Com relação a variação entre os meses, no Ponto $\mathrm{P} 4$ há uma variação significativa entre os volumes de agosto com os meses de fevereiro e março, além de ser observada uma maior variação do mês de janeiro com os demais, devido a este possui um volume maior de fluxo para o ponto.

No Ponto P5 as sextas e quintas-feiras apresentaram diferenças significativas com os demais pontos, sendo observados igualdades entre segunda com terça e quarta feira e das terças com as quartas-feiras. Ao aproximar-se do final da semana, há uma tendência de aumento dos volumes de deslocamentos nestes dias, culminando na sexta-feira, 
inclusive significativamente maior do que nas quintas-feiras. Os meses com as maiores variações foram agosto e outubro, sendo significativamente diferentes dos demais, com os menores valores de fluxo registrados, devido principalmente ao aumento expressivo do fluxo no veraneio.

É importante destacar que o ponto de coleta se localiza no final da Av. Brasil, o qual limita as opções de acesso a outras partes da cidade, e portanto, parte do fluxo incidente destina-se especificamente a atividades de turismo/visitação. Este ponto fornece acesso a uma área do centro com menor densidade (Barra Sul) e ao mesmo tempo local de expressivo lazer noturno e acesso a uma das maiores atrações turísticas do município (teleférico e parque Unipraias). Com isso, o fluxo no ponto demonstra uma maior variação nos fins da semana do que os demais pontos.

O Ponto P6 não apresentou diferença significativa entre dos fluxos diários na semana, demonstrando que os fluxos de visitantes para atividades de lazer/turismo não são suficientes para alterar significativamente a dinâmica viária em dias úteis. Com relação a variação mensal observa-se uma diferença significativa em todos os meses, mesmo com valores, em média, pouco acima nos meses de verão.
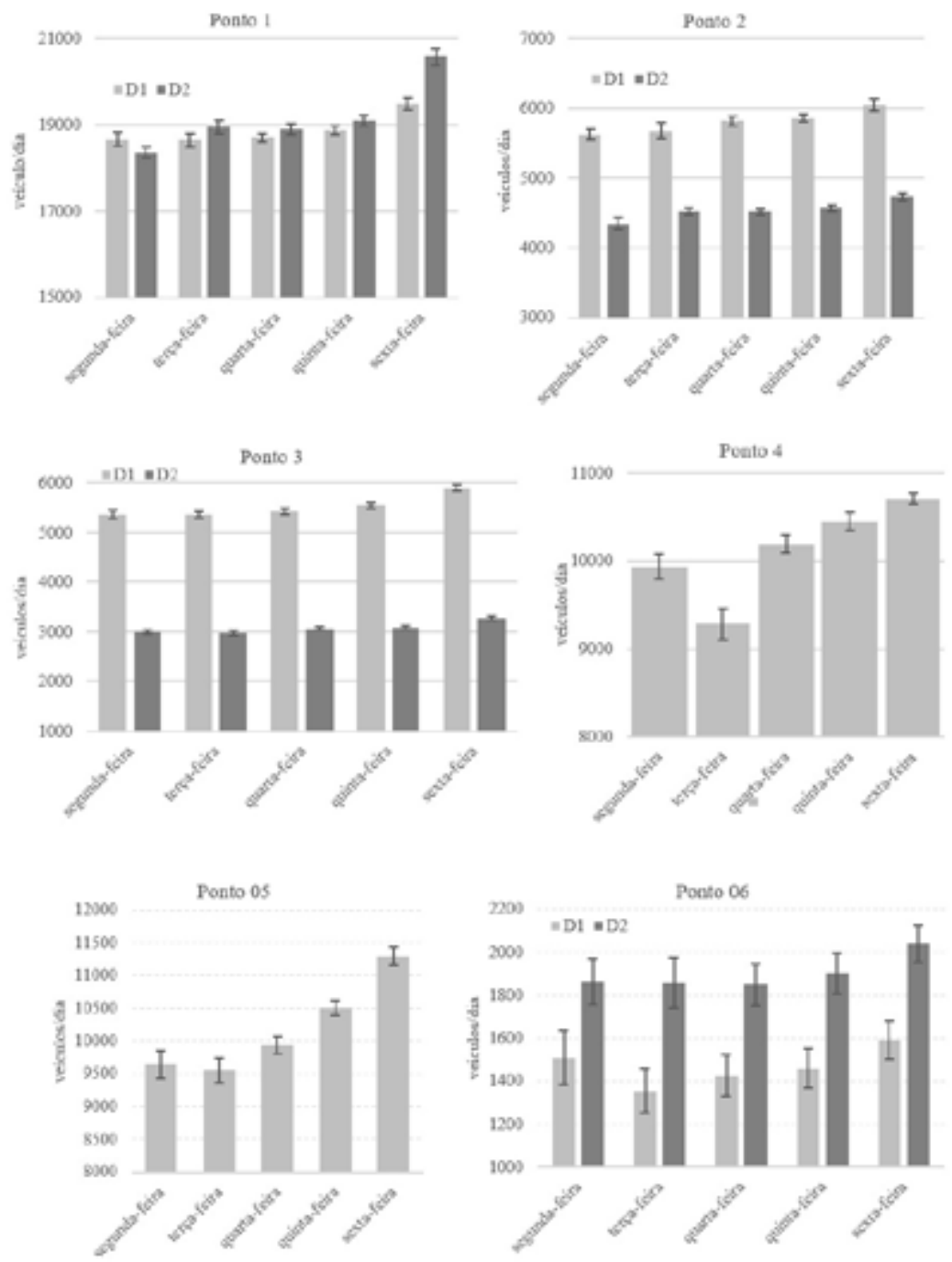

Figura 9. Médias de volumes de tráfego diário em dias úteis nos pontos avaliados e intervalos de confiança associados. Fonte: $O$ Autor. 
Avaliando-se o nível de significância da variação dos volumes entre os dias da semana observa-se que, principalmente, as sextas-feiras possuem um comportamento diferenciado dos demais fluxos. O aumento do fluxo nestes dias pode ser considerado significativo ( $p<0,05$, Quadro 3) em relação aos demais dias da semana em todos os pontos, com exceção do Ponto 6. Neste ponto, apesar do fluxo médio ser maior na sexta feira, a diferença não foi considerada significativa. Como enfatizado na seção de variação horária dos fluxos diários, a dinâmica diferenciada desta localidade faz com que o Bairro não seja afetado significativamente por variações semanais nos volumes de veículos por possuir vocação turística mais concentrada em período especifico do ano durante o período de veraneio. Durante a baixa temporada o fluxo de veículos é movimentado principalmente por residentes locais.

Observa-se ainda um processo de aumento progressivo nos volumes registrados a partir da quinta feira, onde apesar de ser constatada diferença significativa entre quintas e sextas feiras (com exceção aos pontos 4 e 6), no geral, os fluxos das quintas-feiras são significativamente maiores do que as segundas-feiras (com exceção ao ponto 3). A hipótese para este fenômeno é a mesma do que acontece com a sexta-feira, porém, de forma menos intensa. Além disso as segundas feiras é o dia de menor movimentação relacionada a lazer, diminuindo o fluxo de visitantes locais.

Quadro 3. Análise de variância dos volumes diários em dias úteis (Teste-F). Fonte: O Autor.

\begin{tabular}{|l|c|c|c|c|c|c|}
\hline \multirow{2}{*}{ Diferença entre Níveis } & \multicolumn{7}{|c|}{ P-Value } \\
\cline { 2 - 8 } & Ponto 1 & Ponto 2 & Ponto 3 & Ponto 4 & Ponto 5 & Ponto 6 \\
\hline segunda-feira-terça-feira & 0,0961 & 0,1723 & 0,9144 & 0,0001 & 0,7067 & 0,5786 \\
\hline segunda-feira-quarta-feira & 0,0908 & 0,031 & 0,3235 & 0,1903 & 0,2144 & 0,7298 \\
\hline segunda-feira-quinta-feira & 0,0058 & 0,007 & 0,0646 & 0,0094 & 0,0003 & 0,9584 \\
\hline segunda-feira-sexta-feira & 0 & 0 & 0 & 0,0001 & 0 & 0,3725 \\
\hline terça-feira-quarta-feira & 0,978 & 0,4218 & 0,2739 & 0 & 0,1065 & 0,8335 \\
\hline terça-feira-quinta-feira & 0,2618 & 0,1746 & 0,0508 & 0 & 0,0001 & 0,6148 \\
\hline terça-feira-sexta-feira & 0 & 0,0007 & 0 & 0 & 0 & 0,1488 \\
\hline quarta-feira-quinta-feira & 0,2736 & 0,5775 & 0,3852 & 0,1909 & 0,0155 & 0,7693 \\
\hline quarta-feira-sexta-feira & 0 & 0,0086 & 0 & 0,0049 & 0 & 0,2167 \\
\hline quinta-feira-sexta-feira & 0 & 0,0371 & 0,0005 & 0,1247 & 0,0009 & 0,3453 \\
\hline
\end{tabular}

\section{Variação sazonal nos volumes diários}

Considerando-se as variações dos fluxos diários (dias úteis) ao longo dos meses, observa-se uma variação maior entre os meses, sem um padrão definido, apesar de haver mais diferenças significativas entre o mês de inverno com os meses de verão (Quadro 4). Nos pontos 1 e 3 por exemplo, o mês de agosto apresenta-se diferente dos demais (com fluxos menores).

Os pontos 5 e 6 da apresentam diferenças significativas do mês de agosto com os demais com exceção de agosto-outubro e agosto-março no ponto 5. No entanto, o ponto 6, devido a sua característica de balneário de veraneio demonstrou volumes de tráfego significativamente diferente entre os meses, com maiores fluxos nos meses de verão devido ao turismo e menores nos demais meses. 
Quadro 4. Análise de variância dos volumes diários em dias uteis entre os meses (Teste-F). Fonte: O Autor.

\begin{tabular}{|c|c|c|c|c|c|c|}
\hline \multirow[b]{2}{*}{ Diferença entre Níveis } & \multicolumn{6}{|c|}{ P-value } \\
\hline & $\begin{array}{c}P_{1}-\text { Av. do } \\
\text { Estado }\end{array}$ & $\begin{array}{c}\text { P2 - Rua } \\
\text { Dom } \\
\text { Afonso }\end{array}$ & $\begin{array}{c}\text { P3- Rua } \\
\text { Ant. } \\
\text { Bittencourt. }\end{array}$ & $\begin{array}{c}P_{4}-\text { Rua } \\
1500\end{array}$ & $\begin{array}{c}\text { P5 - Av. } \\
\text { Brasil }\end{array}$ & $\begin{array}{c}\text { P6-Rod. } \\
\text { Rodes. } \\
\text { Pavan }\end{array}$ \\
\hline Agosto-Setembro & 0,0033 & 0,1404 & 0,0001 & 0,3575 & 0,0247 & 0,0352 \\
\hline Agosto-Outubro & 0,0081 & 0,1668 & 0,0014 & 0,7113 & 0,5009 & 0,0788 \\
\hline Agosto-Novembro & o & 0 & o & 0,1156 & 0,0196 & 0,0009 \\
\hline Agosto-Dezembro & o & 0 & o & 0,1877 & o & 0 \\
\hline Agosto-Janeiro & 0,0061 & 0,0304 & o & 0,5733 & 0,0001 & o \\
\hline Agosto-Fevereiro & 0,0191 & 0,2211 & $\mathrm{o}$ & 0,0231 & 0,0016 & $\mathrm{o}$ \\
\hline Agosto-Março & 0,0002 & 0,9635 & o & 0,0099 & 0,2402 & o \\
\hline Setembro-Outubro & 0,767 & 0,926 & 0,4111 & 0,5816 & 0,1131 & 0,7225 \\
\hline Setembro-Novembro & 0,0328 & 0,0071 & 0,3786 & 0,5106 & 0,9285 & 0,2095 \\
\hline Setembro-Dezembro & 0,1864 & 0 & 0,1477 & 0,6895 & 0,0396 & 0 \\
\hline Setembro-Janeiro & 0,8418 & 0,4833 & o & 0,139 & 0,069 & o \\
\hline Setembro-Fevereiro & 0,5411 & 0,8001 & 0,0001 & 0,1721 & 0,3412 & o \\
\hline Setembro-Março & 0,43 & 0,1286 & 0,0045 & 0,093 & 0,2777 & 0,0245 \\
\hline Outubro-Novembro & 0,0154 & 0,0054 & 0,0898 & 0,2275 & 0,0943 & 0,1082 \\
\hline Outubro-Dezembro & 0,1064 & o & 0,024 & 0,3423 & 0,0003 & o \\
\hline Outubro-Janeiro & 0,9229 & 0,4274 & o & 0,3512 & 0,0008 & $\mathrm{o}$ \\
\hline Outubro-Fevereiro & 0,7527 & 0,8726 & o & 0,0562 & 0,0118 & o \\
\hline Outubro-Março & 0,2782 & 0,1534 & 0,0003 & 0,0264 & 0,6148 & 0,0095 \\
\hline Novembro-Dezembro & 0,4096 & 0,1051 & 0,568 & 0,7959 & 0,0489 & o \\
\hline Novembro-Janeiro & 0,0199 & 0,0442 & 0,0002 & 0,0334 & 0,0836 & o \\
\hline Novembro-Fevereiro & 0,0064 & 0,0033 & 0,0017 & 0,4773 & 0,3884 & 0,0004 \\
\hline Novembro-Março & 0,175 & 0 & 0,0475 & 0,3041 & 0,2401 & 0,3135 \\
\hline Dezembro-Janeiro & 0,1288 & 0,0003 & 0,0015 & 0,061 & 0,8075 & o \\
\hline Dezembro-Fevereiro & 0,0543 & 0 & 0,0096 & 0,3328 & 0,2641 & 0,3581 \\
\hline Dezembro-Março & 0,5927 & 0 & 0,1559 & 0,1989 & 0,0019 & 0,0006 \\
\hline Janeiro-Fevereiro & 0,6805 & 0,3404 & 0,5421 & 0,0048 & 0,3819 & o \\
\hline Janeiro-Março & 0,3231 & 0,0272 & 0,0723 & 0,0018 & 0,004 & o \\
\hline Fevereiro-Março & 0,1624 & 0,2045 & 0,2325 & 0,7503 & 0,0427 & 0,0108 \\
\hline
\end{tabular}

Considerando-se uma variação do fluxo bruto entre o mês de maior e menor fluxo, Janeiro e Agosto, (Com exceção do P3 onde o mês de maior fluxo é Fevereiro) observam-se variações menos substanciais nos pontos 1,2 e 4 . Nestes pontos, a influência sazonal não é expressiva por serem vias de fluxo intenso e em muitos horários os volumes encontram-se próximos aos fluxos de saturação, não sofrendo influência direta como pontos mais próximos de áreas de fluxo intenso de turismo, como os pontos 3 , 5 e 6 (Figura 10).

Os pontos 1, 2 e 4 localizam-se em vias de importância que vão independem do turismo, sendo vias que interligam diferentes regiões da área urbana, dão acesso a outros municípios e importantes eixos comerciais e de serviço no município.

Merece destaque o ponto6, com a maior variação identificada. Como já ressaltado está área situa-se em área afastada do centro da cidade, com baixa densidade demográfica, no entanto, com predomínio de atividades voltadas ao turismo. Sendo identificada uma diferença de fluxo de cerca de $85,6 \%$ entre janeiro e agosto. A Av. 
Brasil (P5), apesar de ser muito movimentada o ano inteiro, apresentou uma considerável influência dos meses de verão, com aumento acumulado de cerca de 15,4\% no fluxo entre agosto-janeiro.

O P3 apesar de situado próximo a Av. do Estado, demonstrou uma sensibilidade a variação dos fluxos sazonais (16\% entre agosto-fevereiro). Esta via encontra-se em localidade com influência direta do turismo de veraneio, sendo a via coletora mais importante desta localidade, devido a estabelecer conexão entre sul e norte da localidade sendo de duplo sentido, diferente das demais, o que facilita o acesso a saída do município (norte), para o centro, praia e a região sul do município, com acesso direto a principal via do município (Avenida do Estado).

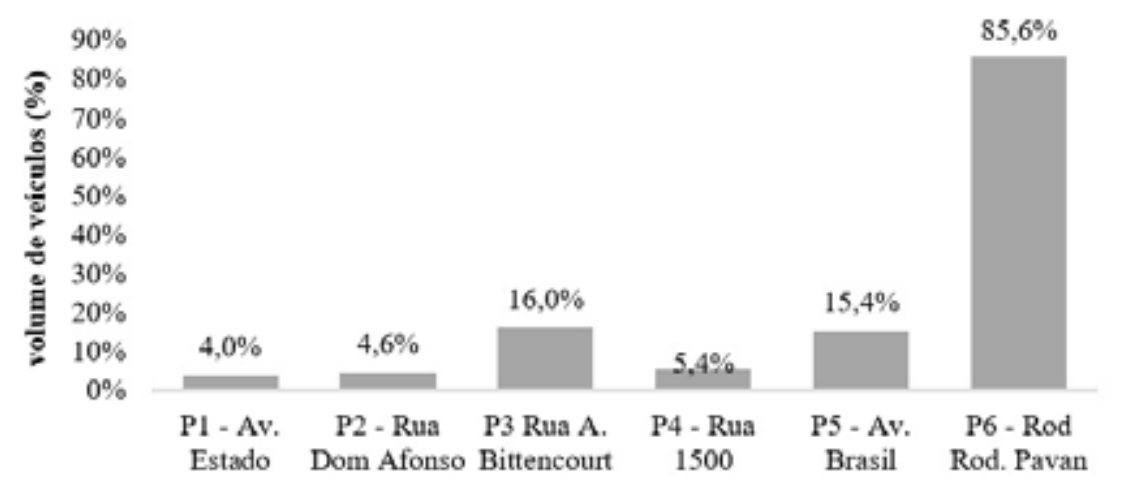

Figura 10. Evolução dos volumes de tráfego entre os meses de menor e maior fluxo nos dias úteis para os pontos analisados. Fonte: $\mathrm{O}$ autor.

\section{Fim de semana e feriados}

Com relação a variação dos fluxos nos de veículos nos dias não-úteis ao longo dos meses, como sábado, domingo e feriados, observa-se uma variação significativa, principalmente entre meses de inverno e verão, atestando a influência do turismo no município (Figura 13 e 14). Destaca-se que os meses onde os fins de semana foram mais díspares foram principalmente entre o mês de agosto com os demais analisados $(\mathrm{p}<0,05)$, com destaque para a diferença entre os meses de agosto e janeiro onde, com exceção do ponto localizado na Av. Brasil, em todos os demais a hipótese de igualdade pode ser rejeitada. Observa-se que nesta via, os fluxos durante fins de semana são expressivos, sobretudo em dias de sol (Figura 11) devido a condução de visitantes para a Barra Sul do município. Já em pontos como o P1 e P4 (Figura 12) os fluxos são intensos em dias da semana, porém em fins de semana há redução expressiva no fluxo. 


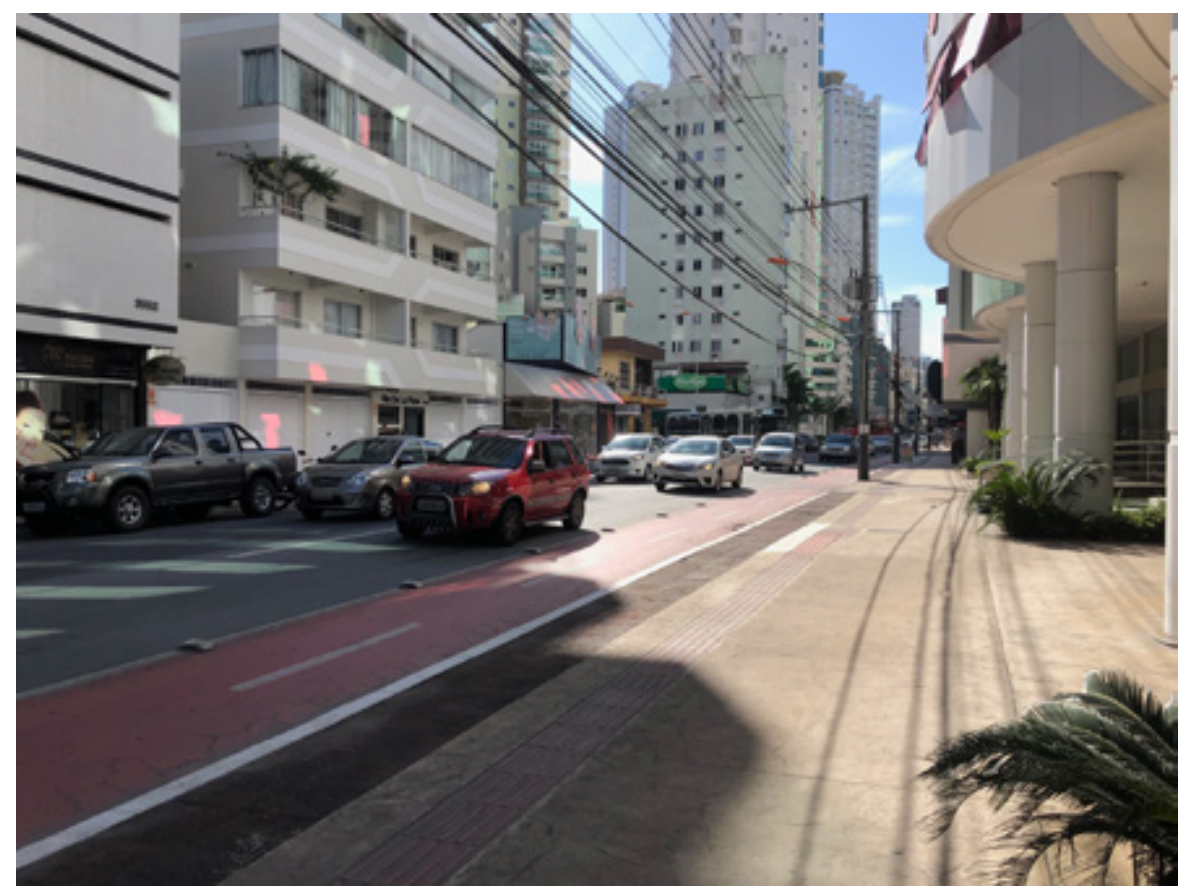

Figura 11. Fluxo de veículos na Avenida Brasil em final de semana. Fonte: $O$ autor.

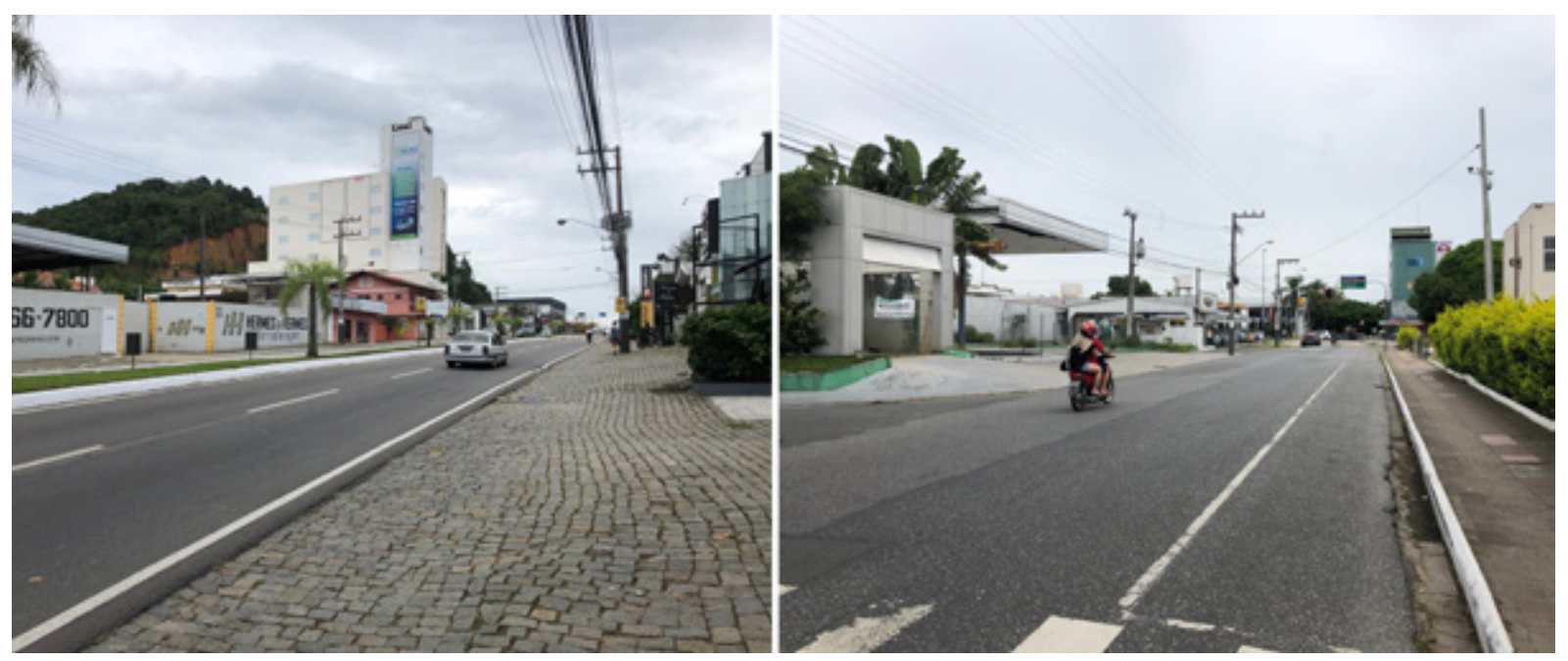

Figura 12. Fluxo de veículos na Av. do Estado $\left(P_{1}\right)$ e Rua $1500\left(P_{4}\right)$ em final de semana. Fonte: $O$ autor.

Ainda, agosto e fevereiro mostram grandes diferenças, principalmente em domingos e feriados, com um fluxo muito superior ao de agosto, por exemplo. Foi observado ainda, uma semelhança entre meses intertemporada, onde não houve diferença significativa entre os meses de outubro-março e novembro e dezembro, assim como entre os meses com o fluxo é maior, janeiro-fevereiro (Quadro 5). 


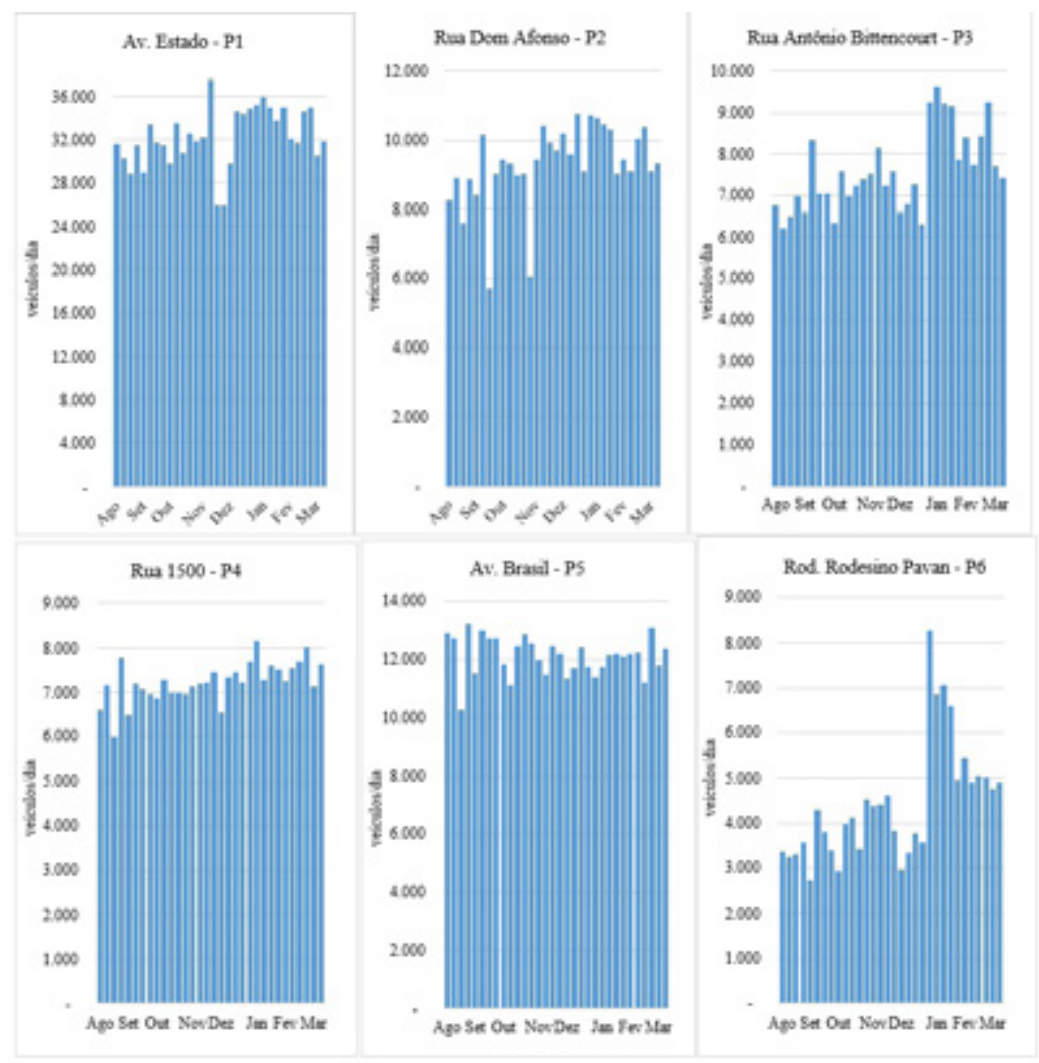

Figura 13. Fluxo diário acumulado nos pontos de estudo para os Sábados. Fonte: O Autor.

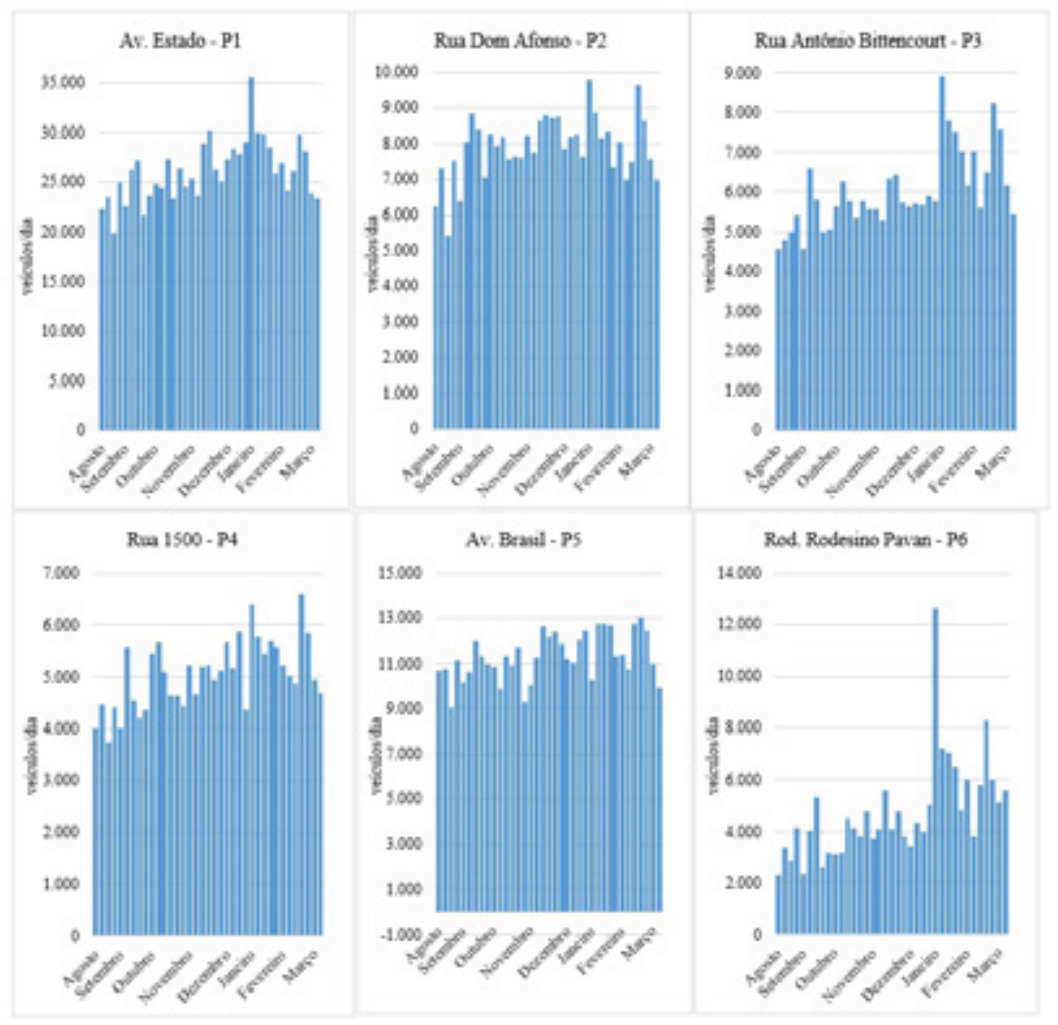

Figura 14. Fluxo diário acumulado para os pontos de estudo em Domingos e feriados. Fonte: $O$ autor. 
Quadro 5. Variação sazonal dos fluxos diários em finais de semana e feriados. Teste-F. Fonte: $O$ autor.

\begin{tabular}{|c|c|c|c|c|c|c|c|c|c|c|c|c|}
\hline \multirow{3}{*}{$\begin{array}{l}\text { Diferença entre } \\
\text { Níveis }\end{array}$} & \multicolumn{12}{|c|}{ P-Value } \\
\hline & \multicolumn{6}{|c|}{ Sábados } & \multicolumn{6}{|c|}{ Domingos e feriados } \\
\hline & $\begin{array}{c}\text { Av. } \\
\text { Estado }\end{array}$ & $\begin{array}{c}\text { Rua } \\
\text { Dom } \\
\text { Afonso }\end{array}$ & $\begin{array}{l}\text { Rua A. } \\
\text { Bitt. }\end{array}$ & $\begin{array}{l}\text { Rua } \\
1500\end{array}$ & $\begin{array}{c}\text { Av } \\
\text { Brasil }\end{array}$ & $\begin{array}{l}\text { Rod } \\
\text { Rod. } \\
\text { Pavan }\end{array}$ & $\begin{array}{c}\text { Av. } \\
\text { Estado }\end{array}$ & $\begin{array}{c}\text { Rua } \\
\text { Dom } \\
\text { Afonso }\end{array}$ & $\begin{array}{c}\text { Rua A. } \\
\text { Bitt. }\end{array}$ & $\begin{array}{l}\text { Rua } \\
1500\end{array}$ & $\begin{array}{c}\text { Av } \\
\text { Brasil }\end{array}$ & $\begin{array}{l}\text { Rod } \\
\text { Rod. } \\
\text { Pavan }\end{array}$ \\
\hline Agosto-Setembro & 0,640 & 0,906 & 0,209 & 0,865 & 0,666 & 0,794 & 0,311 & 0,043 & 0,342 & 0,291 & 0,355 & 0,742 \\
\hline Agosto-Outubro & 0,526 & 0,838 & 0,340 & 0,630 & 0,831 & 0,573 & 0,128 & 0,027 & 0,111 & 0,025 & 0,690 & 0,463 \\
\hline Agosto-Novembro & 0,926 & 0,055 & 0,055 & 0,207 & 0,605 & 0,206 & 0,020 & 0,002 & 0,071 & 0,015 & 0,049 & 0,253 \\
\hline Agosto-Dezembro & 0,079 & 0,031 & 0,221 & 0,208 & 0,282 & 0,176 & 0,002 & 0,015 & 0,097 & 0,004 & 0,055 & 0,313 \\
\hline Agosto-Janeiro & 0,021 & 0,027 & 0,000 & 0,014 & 0,643 & 0,000 & 0,000 &, & 6,000 & 0,000 & 0,022 & 0,000 \\
\hline Agosto-Fevereiro & 0,124 & 0,081 & 0,001 & 0,015 & 0,838 & 0,025 & 0,010 & 0,007 & 0,000 & 0,001 & ,015 &, 009 \\
\hline Agosto-Março & 0,736 & 0,284 & 0,070 & 0,089 & 0,710 & 0,056 & 0,536 & 0,237 & 0,075 & 0,065 & 0,936 & 0,039 \\
\hline Seter & o & 77 & o & 0,754 & o & 1 & 0,595 & 27 & 3 & 0 & 6 & 684 \\
\hline Setembro-Novembro & 0,575 & 0,043 & 0,475 & 0,272 & 0,346 & 0,311 & 0,163 & 0,171 & 0,371 & 0,145 & 0,274 & 0,411 \\
\hline Setem & 0,100 & 0,024 & 0,973 & 0,272 & 0,137 & 0,209 & $0,0<1$ & 0,629 & 0,460 & 0,050 & 298 & 0,494 \\
\hline Setembro-Janeiro & 0,056 & 0,021 & 0,002 & 0,020 & 0,374 & 0,001 & 0,001 & 0,168 & 0,000 &, 002 &, 151 & 0,000 \\
\hline Setembro-Fevereiro & 0,273 & 0,064 & 0,024 & 0,022 & 0,526 & 0,045 & 0,093 & 0,445 & 0,002 & 0,010 & 0,108 & 0,020 \\
\hline Setembro-Março & 0,896 & 0,236 & 0,554 & 0,123 & 0,424 & 0,094 & 0,688 & 0,373 & 0,386 & 0,408 & 0,398 & 0,078 \\
\hline Outubro-Novembro & 0,468 & 0,083 & 0,307 & 0,428 & 0,760 & 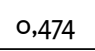 & 0,378 & 0,247 & 0,820 & 0,830 & 0,110 & 0,676 \\
\hline Outubro-Dezembro & 0,246 & 0,047 & 0,779 & 0,428 & 0,385 & 0,418 & 0,067 & 0,791 & 0,944 & 0,450 & 0,121 & 0,780 \\
\hline Outubro-Janeiro & 0,079 & 0,042 & 0,001 & 0,040 & 0,802 & 0,002 & 0,005 & 0,243 & 0,001 & 0,034 & 0,054 & 0,001 \\
\hline Outubro-Fevereiro & 0,351 & 0,120 & 0,012 & 0,043 & 0,993 & 0,082 & 0,239 & 0,584 & 0,012 & 0,146 & 0,036 & 0,050 \\
\hline Outubro-Março & 0,765 & 0,382 & 0,367 & 0,212 & 0,874 & 0,164 & 0,354 & 0,269 & 0,842 & 0,661 & 0,750 & 0,168 \\
\hline Nover & 66 & 81 & 0,454 & 0,999 & 0,570 & 0,924 & 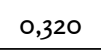 & 7 & 75 & 37 & 0,958 & 90 \\
\hline Novembro-Janeiro & 0,017 & 0,736 & 0,012 & 0,184 & 0,957 & 0,010 & 0,042 & 0,993 & 0,002 & 0,054 & 0,722 & 0,003 \\
\hline Novembro-Fevereiro & 0,104 & 0,846 & 0,104 & 0,195 & 0,753 & 0,289 & 0,761 & 0,535 & 0,020 & 0,211 & 0,590 & 0,116 \\
\hline Novembro-Março & 0,667 & 0,367 & 0,902 & 0,640 & 0,883 & 0,485 & 0,076 & 0,028 & 77 & 0,515 & 0,058 & 329 \\
\hline Dezembro-Janeiro & 0,525 & 0,953 & 0,002 & 0,184 & 0,534 & 0,012 & 0,275 & 0,363 & 0,001 & 0,155 & 0,683 & 0,002 \\
\hline Dezembro-Fevereiro & 0,814 & 0,637 & 0,022 & 0,195 & 0,380 & 0,332 & 0,487 & 0,776 & 0,014 & 0,472 & 0,554 & 0,089 \\
\hline Dezembro-Março & 0,149 & 0,241 & 0,531 & 0,639 & 0,476 & $(0,3)$ & 0,008 & 0,174 & 0,897 & 0,236 & 0,065 & 0,266 \\
\hline Janeiro-Fevereiro & 0,386 & 0,596 & 0,312 & 0,972 & 0,795 & 0,096 & 0,080 & 0,529 & 0,310 & 0,470 & 0,854 & 0,107 \\
\hline Janeiro-Março & 0,043 & 0,220 & 0,009 & 0,381 & 0,926 & 0,046 & 0,000 & 0,028 & 0,001 & 0,012 & 0,027 & 0,030 \\
\hline Fevereiro-Março & 0,222 & 0,477 & 0,082 & 0,399 & 0,867 & 0,710 & 0,041 & 0,104 & 0,019 & 0,062 & 0,018 & 0,535 \\
\hline
\end{tabular}

\section{Composição do tráfego}

A composição dos veículos nos fluxos de tráfego viário apresentou predominância de automóveis de passageiros (carros), correspondendo a mais de dois terços do volume nos pontos analisados (Figura 10). O ponto com a maior concentração de carros foi o localizado na Av. Brasil, onde a média mensal dos fluxos diários somaram $87 \%$ do fluxo. Nos pontos 1 e 3 a participação dos carros correspondem a $80 \%$ do fluxo. O ponto com a menor concentração média de carros no fluxo foi o ponto P6, com a participação dos carros em $73 \%$ do volume.

O predomínio de viagens de automóveis individuais no município pode ser explica pela combinação de dois fatores. Por um lado a deficiência no transporte público estimula o acesso a veículos individuais (carros, ou moto) e por outro a maior renda 
per capita geral das famílias, onde a participação do uso de transportes coletivo apontado pelo diagnóstico do Plano de mobilidade do município (PMBC, 2018) é cerca de $7 \%$, bem abaixo da média no país de $28 \%$ (ANTP, 2018). O mesmo estudo apontou que a baixa procura pelo transporte público no município é a oferta improdutiva, ausência de informações ao usuário nos pontos de ônibus, redes e linhas inadequadas e quilometragem ociosa.

O segundo volume de maior frequência foram as motocicletas, com volume variando entre 9-21\% do fluxo, sendo a maior parcela no P2, junto a Rua Dom Afonso, via que recebe grande fluxo pendular de trabalhadores do município de Camboriú, com parcela expressiva de deslocamentos feitos por motocicletas (21\%). Os pontos 1, 3 e 4 possuem volumes semelhantes entre 14-18\%. Os pontos de menor volume de tráfego de motocicleta são os pontos 5 e 6, atingindo 9\% na Av. Brasil (P5).

No geral motocicletas estão associado com deslocamentos por motivo de trabalho, utilizando-se de rotas de acesso rápido (vias arteriais e coletora), como o caso dos pontos $1,2,3$ e 4 que constituem importantes rotas de acesso a outros bairros e municípios. Isso gera um elevado volume deste modo popular principalmente por população de baixa renda devido a menores custos de aquisição/ manutenção, e redução no tempo de deslocamento, a exemplo mostrado pela Figura 15.
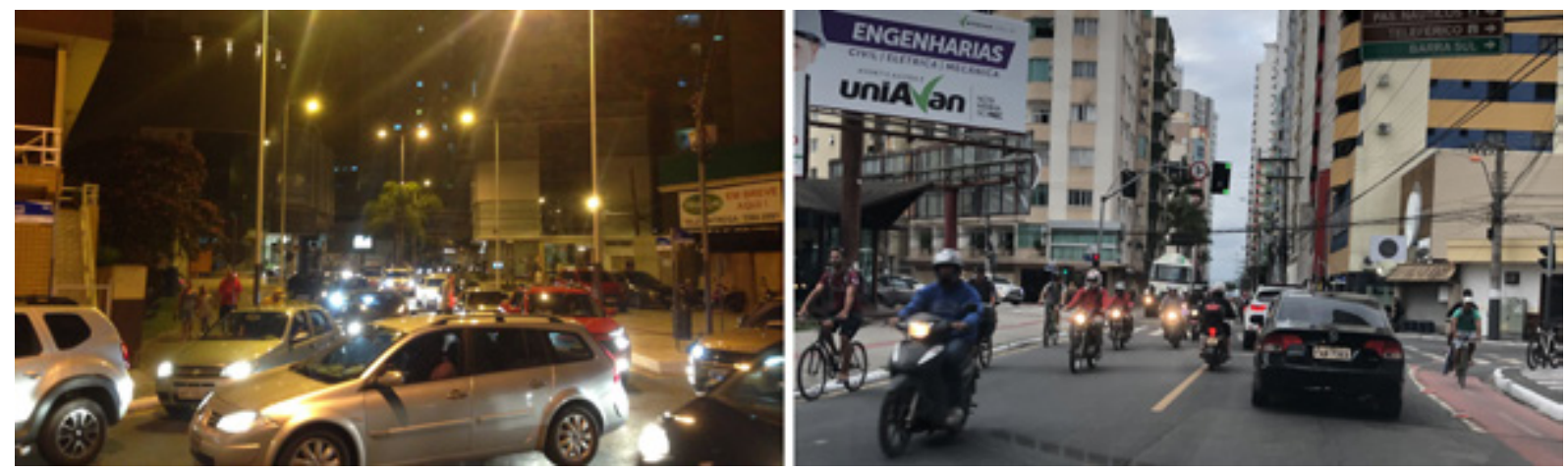

Figura 15. Exemplo de diferenças da composição próximos ao P3. Foto da esquerda ressalta fluxo de veículos em sábado, com destino principal de lazer (esquerda) e movimento intenso de motocicletas, principalmente trabalhadores, retornando de expediente de trabalho deixando a região central da cidade no horário de pico da tarde (direita). Fonte: $\mathrm{O}$ autor.

Os fluxos de ônibus e caminhões correspondem as menores participações nos fluxos, abaixo de 3\%, com exceção para o P6, localizado na Região das Praias, onde o fluxo de ônibus atingiu $11 \%$. Neste ponto o fluxo de veículos é baixo fora de período de veraneio, no entanto a circulação de ônibus de linha é periódica, o que pode contribuir para uma maior participação destes veículos. 

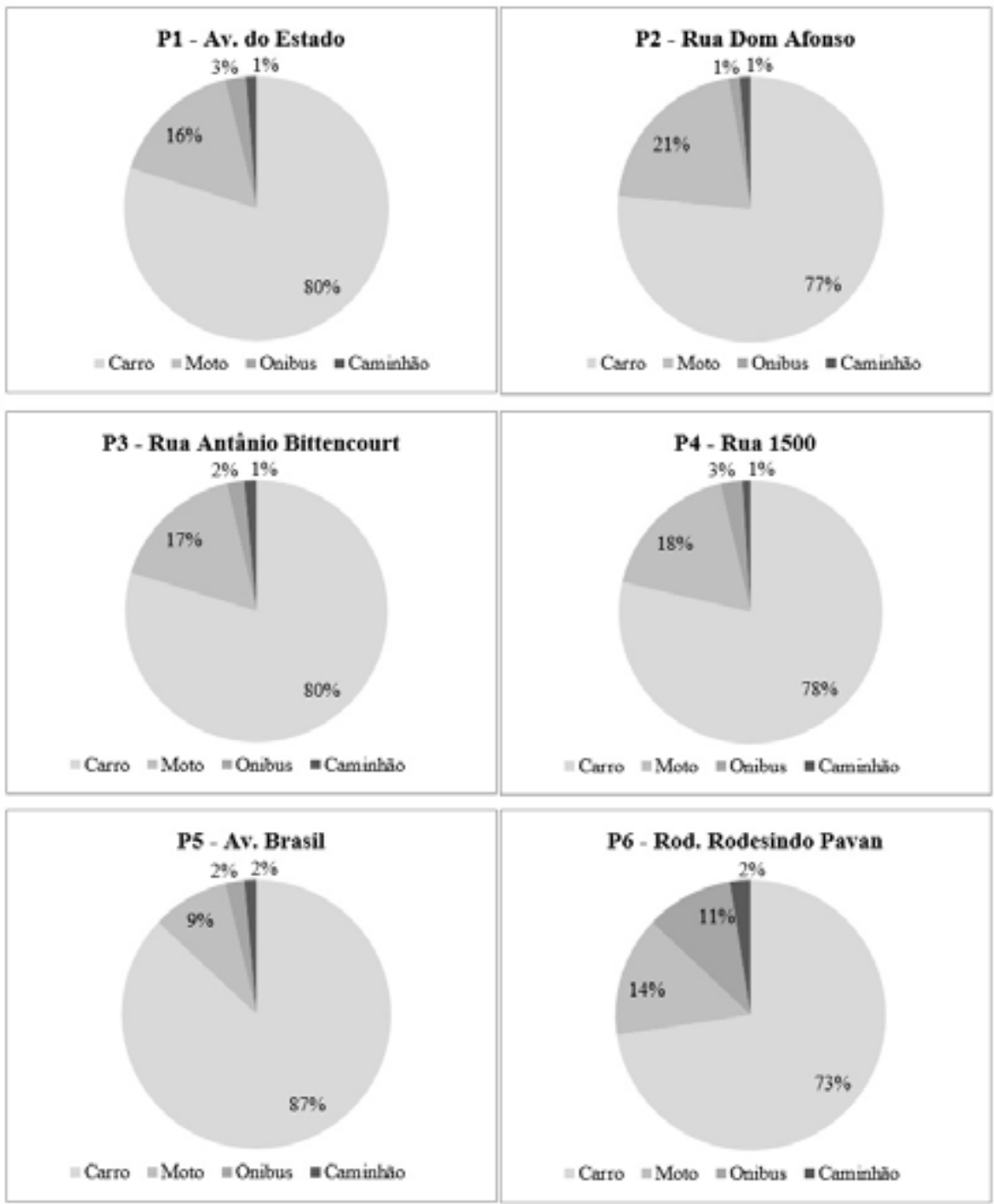

Figura 16. Composição do fluxo de veículos nos pontos analisados. Fonte: O Autor.

Com relação a variação da composição do tráfego se verifica que não há variação significativa da proporção de carros ao longo dos meses de monitoramento, com exceção de um caso entre os meses de outubro-março, no P2, com variações significativas em todos os veículos da composição (Quadro 6). É interessante ressaltar a existência de padrão nos deslocamentos de carros e motocicletas, onde mesmo o fluxo variando de forma sazonal, a proporção mantém-se estatisticamente constante.

A proporção de motocicletas, igualmente permanece constante na maioria das comparações, sendo iguais nos $\mathrm{P} 4$, P5 e P6, e com mudanças pontuais nos $\mathrm{P} 1$ e P2. O P3 apresentou as maiores variações na composição do fluxo de motocicletas, em que, principalmente, o mês de agosto apresentou um menor fluxo de destas em comparação com os demais meses. No P2 ocorreu a maior quantidade de dispersão nos dados de veículos pesados, onde há uma variação significativa no volume destes, sem a definição de padrão. Há que se ressaltar que categorias com baixo volumes de veículos, como caminhões e ônibus, tendem a gerar mais variações nas análises estatísticas, sendo que pequenas variações no fluxo alteram substancialmente o comportamento do grupo. 
Quadro 6. Análise de variância entre os meses para dados de composição do tráfego por ponto avaliado. Os campos marcados referem-se as comparações onde a variação entre os níveis foi significativa pelo teste de Fisher $(p<0,05)$. Fonte: $O$ Autor.

\begin{tabular}{|c|c|c|c|c|c|c|c|c|c|c|c|c|c|c|c|c|c|c|c|c|c|c|c|c|}
\hline \multirow[b]{3}{*}{ Níveis } & \multicolumn{24}{|c|}{ Valores de $\mathrm{p}<0,05$} \\
\hline & \multicolumn{4}{|c|}{$P_{1}$} & \multicolumn{4}{|c|}{$P_{2}$} & \multicolumn{4}{|c|}{$P_{3}$} & \multicolumn{4}{|c|}{$\mathrm{P}_{4}$} & \multicolumn{4}{|c|}{$P_{5}$} & \multicolumn{4}{|c|}{ P6 } \\
\hline & 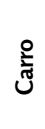 & $\stackrel{\circ}{\stackrel{0}{0}}$ & 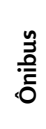 & & ํㅗㅀ & $\stackrel{\circ}{\stackrel{0}{0}}$ & 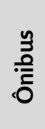 & 疍 & 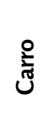 & $\frac{8}{\Sigma}$ & 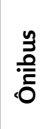 & 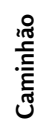 & 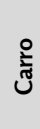 & $\stackrel{0}{\circ}$ & 气̆ & 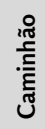 & 옳 & $\stackrel{\circ}{\stackrel{0}{2}}$ & 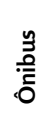 & 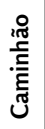 & 옳 & $\stackrel{\circ}{\Sigma}$ & 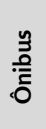 & 疍 \\
\hline DEZ-AGO & & & & & & & $x$ & $x$ & & & & & & & & & & & & & & & & \\
\hline FEV-AGO & & $x$ & & & & & $x$ & $x$ & & $x$ & & & & & & & & & & & & & & \\
\hline JAN-AGO & & & & & & & $x$ & $x$ & & $x$ & & & & & & & & & & $x$ & & & & $x$ \\
\hline MAR-AGO & & $x$ & & & & & $x$ & $x$ & & $x$ & & & & & & & & & & & & & & \\
\hline NOV-AGO & & & & & & & $x$ & $x$ & & $x$ & & & & & & & & & & & & & & $x$ \\
\hline OUT-AGO & & & & & & & $x$ & $x$ & & & & & & & & & & & & & & & & \\
\hline SET-AGO & & & & & & & $x$ & $x$ & & $x$ & & & & & & & & & & & & & & \\
\hline \multicolumn{25}{|l|}{ FEV-DEZ } \\
\hline \multicolumn{25}{|l|}{ JAN-DEZ } \\
\hline MAR-DEZ & & & & & & & $x$ & & & & & & & & & & & & & & & & & \\
\hline NOV-DEZ & & & & & & & $x$ & $x$ & & & & & & & & & & & & & & & & \\
\hline OUT-DEZ & & & & & & & $x$ & $x$ & & & & & & & & & & & & & & & & \\
\hline \begin{tabular}{|l|} 
SET-DEZ \\
\end{tabular} & & & & & & & $x$ & $x$ & & & & & & & & & & & & & & & & \\
\hline \multicolumn{25}{|l|}{ JAN-FEV } \\
\hline \multicolumn{25}{|l|}{ MAR-FEV } \\
\hline NOV-FEV & & & & & & & $x$ & $x$ & & & & & & & & & & & & & & & & \\
\hline OUT-FEV & & & & & & & $x$ & $x$ & & $x$ & & & & & & & & & & & & & & \\
\hline SET-FEV & & & & & & & $x$ & $x$ & & & & & & & & & & & & & & & & \\
\hline MAR-JAN & & & & & & & $x$ & & & & & & & & & & & & & & & & & \\
\hline NOV-JAN & & & & & & & $x$ & $x$ & & & & & & & & & & & & $x$ & & & & \\
\hline OUT-JAN & & & & & & & $x$ & $x$ & & & & & & & & & & & & $x$ & & & & \\
\hline SET-JAN & & & & & & & $x$ & $x$ & & & & & & & & & & & & $x$ & & & & \\
\hline NOV-MAR & & & & & & & $x$ & $x$ & & & & & & & & & & & & & & & & \\
\hline OUT-MAR & & & & & $x$ & $x$ & $x$ & $x$ & & $x$ & & & & & & & & & & & & & & \\
\hline SET-MAR & & & & & & & $x$ & $x$ & & & & & & & & & & & & & & & & \\
\hline \multicolumn{25}{|l|}{ OUT-NOV } \\
\hline \multicolumn{25}{|l|}{ SET-NOV } \\
\hline SET-OUT & & & & & & & & & & & & & & & & & & & & & & & & \\
\hline
\end{tabular}

\section{Conclusão}

A metodologia aplicada mostrou-se sensível para identificar as variações sazonais nos fluxos, atestando que há alteração significativa no fluxo gerado pela população flutuante incidente no município, considerando que a base de dados disponíveis de agosto a março. Destaca-se ainda, o P5, localizado na Av. Brasil, em alguns períodos apresentou uma média de fluxo menor nos meses de inverno do que de verão, mesmo havendo uma densidade demografia superior nos meses de veraneio, em alguns momentos a via encontra-se saturada de veículos, o que reduz a velocidade de fluxo e consequentemente o registro de veículos por hora, fenômeno este, comumente observado em alguns dias de pico no verão. 
Se por um lado ficou evidente a variação sazonal nos fluxos de veículos, com crescimento nos meses de verão, por outro lado a variação entre os meses (mesmo significativa) é baixa comparativamente a proporção de turistas existentes no município. Isso se dá por dois fatores, o primeiro se deve a forma compacta da cidade (alta densidade demográfica), onde muitos visitantes ao se instalarem na cidade não usam seus veículos intensivamente e o segundo se refere as questões de incompatibilidade geométricas das vias onde, mesmo possuindo uma demanda maior por viagens em determinados momentos, maiores fluxos são inviabilizados pois a maioria das vias de maior hierarquia na cidade já operam em regime próximo a saturação, mesmo na baixa temporada.

Isto está diretamente associado a fatores urbanos e de planejamento dos transportes no município. Devido a densidade demográfica elevada do município, há uma maior concentração de viagens potenciais por unidade de área. Isso combinado a uma subutilização de transporte público, naturalmente as vias operaram próximas a sua capacidade e, não raro, com fluxo saturado em níveis de serviço críticos.

Dessa forma, mesmo adotando-se ações de ampliação de faixas de tráfego, estas serão preenchidas por veículos, caracterizando o fenômeno do tráfego induzido. Ficando claro, portanto, a necessidade de novas estratégias que favoreçam a implementação de transporte coletivo eficiente.

Interessante ressaltar que nos pontos próximos às divisas do município de Balneário Camboriú com Itajaí (P1) e com Camboriú (P2) foi possível confirmar e caracterizar os fluxos pendulares existentes. No primeiro, o movimento pendular se dá por trabalhadores que residem em Balneário Camboriú e trabalham em Itajaí, e no segundo, de trabalhadores de Camboriú que trabalham em Balneário Camboriú. Essa caracterização é importante para subsidiar políticas e intervenções regionais, demostrando que a questão de mobilidade urbana deve ser entendida considerando os deslocamentos intra e intermunicipais.

A geração de informações para o planejamento urbano do município deve ser realizada de forma continuada, sendo recomendado ao poder público municipal ampliar a rede de monitoramento de veículos e a disponibilização destes dados, além da ampliação da série histórica, pesquisas de origem-destino, etc., de forma que estes possam ser incorporados ao planejamento, consistindo em investimento e não custo. Estes fatos não se restringem a cidade de estudo, mas é uma realidade necessária em todos os municípios, sobretudo em município de médio e grande porte, com problemas mais crônicos resultantes do tráfego e necessitam de dados consistentes para melhorar a gestão pública.

À pesquisadores recomenda-se aprofundar pesquisas relacionadas ao aprimoramento de metodologias de determinação de parâmetros de desempenho de tráfego baseadas em pesquisas amostrais, para que subsidie estudos relacionados a impactos de transportes, como tempo de atraso, velocidades médias de fluxo, consumo de combustíveis, emissão de poluentes, etc. Cabe ainda a realização de pesquisas que relacionem indicadores econômicos dos valores perdidos no atual modelo de mobilidade comparativamente com outras modalidades de transportes.

AGRADECIMENTOS: A Coordenação de Aperfeiçoamento de Pessoal de Nível Superior (CAPES) pelo financiamento e ao Fundo Municipal de Trânsito de Balneário Camboriú (FUMTRAN) pela colaboração e fornecimento de dados. 


\section{Q Bibliografia}

»Alzate, J. M. et al. (2007). Modelos para analizar el desarrollo del transporte urbano del Valle de Aburrá con consideraciones económicas, energéticas y ambientales. rev.ing. Bogotá 25, 114-121.

» ANTP - Associação Nacional de Transportes Públicos. (1999). Redução das deseconomias urbanas com a melhoria do transporte público. Instituto de Pesquisa Econômica Aplicada - Associação Nacional dos Transportes Públicos. Revista dos Transportes Públicos 21, 35-92.

» ANTP - Associação Nacional de Transportes Públicos. (2018). Sistema Nacional de Informação da Mobilidade Urbana. Relatório geral 2016. Maio de 2018.

»Banister, D. (2015). Great Cities and Their Traffic: Michael Thomson Revisited. Built Environment 41(3), 435-446.

"Camagni, R., Gibelli, M. C., y Rigamonti, P. (2002). Urban mobility and urban form: the social and environmental costs of different patterns of urban expansion. Ecological Economics 40 (2), 199-216.

»Cohen, A., y Castillo, O. S. (2017). Ruido en la ciudad. Contaminación auditiva y ciudad caminable. Estud. demogr. urbanos, México 32 (1), 65-96.

»DNIT - Departamento Nacional de Infraestrutura de Transportes (2006). Manual de Estudos de Tráfego. Ministério dos Transportes. Publicação IPR - 723.

»DNIT - Departamento Nacional de Infraestrutura De Transportes. (2016). Plano Nacional de Contagem de Tráfego - PNCT. Brasília. Disponível em: < http://www. dnit.gov.br/planejamento-e-pesquisa/planejamento/contagem-de-trafego>.

»Ewing, R., y Cervero, R. (2017). Does Compact Development Make People Drive Less? The Answer Is Yes. Journal of the American Planning Association 83 (1), 1925. doi:10.1080/01944363.2016.1245112

" Figueroa, O. (2005). Transporte urbano y globalización. Políticas y efectos en América Latina. Revista Eure XXXI (94), 41-53.

»Gebeyehu, M.,y Takano, S. (2007). Diagnostic Evaluation of Public Transportation Mode Choice in Addis Ababa. Journal of Public Transportation 10 (4): 27-50.

» Gomes, N. G. U. (2010). Trânsito e o turismo na cidade Caldas Novas - GO. Caminhos de Geografia Uberlândia 13 (33), 27-39.

»IBGE (a) - Instituto Brasileiro de Geografia e Estatística. (2016). Arranjos populacionais e concentrações urbanas do Brasil. 2 ed. Ministério do Planejamento, Desenvolvimento e Gestão, Rio de Janeiro.

»IBGE (b) - Instituto Brasileiro de Geografia e Estatística. (2016). Estimativas de população para $1^{\circ}$ de julho de 2015 e 2016. Ministério do Planejamento, Desenvolvimento e Gestão, Rio de Janeiro.

»IBGE - Instituto Brasileiro de Geografia e Estatística. (2018). Estimativas da população residente no Brasil e unidades da federação com data de referência em $1^{\circ}$ de julho de 2018. Ministério do Planejamento, Desenvolvimento e Gestão, Rio de Janeiro.

»IPEA - Instituto de Pesquisa Econômica Aplicada. (2013). Indicadores de Mobilidade Urbana: PNAD 2012. Secretaria de Assuntos Estratégicos da 
Presidência da República, Rio de Janeiro. N. 161. 17p.

» Khreis, H. et al. (2016). The health impacts of traffic-related exposures in urban areas: Understanding real effects, underlying driving forces and co-producing future directions. Journal of Transport \& Health 3 (3), 249-267.

»Lee, B. K. et al. (2005). Analysis of impacts on urban air quality by restricting the operation of passenger vehicles during Asian Game events in Busan, Korea. Atmospheric Environment 39, 2323-2338.

»Liu, Z., y Sharma, S. (2006). Statistical Investigations of Statutory Holiday Effects on Traffic Volumes. Transportation Research Record: Journal of the Transportation Research Board, No. 1945, Transportation Research Board of the National Academies, Washington, D.C. 40-48.

» NTU - Associação Nacional de Empresas de Transportes Urbanos. (2017). Pesquisa mobilidade da população urbana 2017. Confederação Nacional do Transporte - CNT, Associação Nacional das Empresas de Transportes Urbanos - NTU. - Brasília: CNT: NTU.

»Oliveira, M. V. T. (2004). A natureza dos padrões de variação espaço-temporal do volume veicular em ambiente urbano: estudo de caso em fortaleza. Dissertação (Mestrado). Mestrado em Engenharia de Transportes. Universidade Federal do Ceará.

"Pepe, P. G., Rodrigues, M. G., y Mello, J. A. (2010). Qualidade da informação dos sistemas de gerenciamento de tráfego. XIII Seget, Simpósio de Excelência em Gestão e Tecnologia. Resende.

» PMBC - Prefeitura Municipal de Balneário Camboriú (2017). Fluxo Turístico de Balneário Camboriú. Secretaria de Turismo: Balneário Camboriú.

»PMBC - Prefeitura Municipal de Balneário Camboriú. (2018). Plano de Mobilidade: Leitura do cenário atual. Consultran. Secretaria de Urbanismo, 106p. Balneário Camboriú.

"Pontes, T. F. (2010). Avaliação da Mobilidade Urbana na área metropolitana de Brasília. Dissertação (Mestrado). Universidade de Brasília. Brasília.

» Resende, P. T. V., y Sousa, P. R. (2009). Mobilidade urbana nas grandes cidades brasileiras: Um estudo sobre os impactos do congestionamento. Fundação Dom Cabral. Nova Lima. Caderno de ideias Clo910, 26p.Nova Lima.

" Rubim, B., y Leitão, S. (2013). O plano de mobilidade urbana e o futuro das cidades. Estudos Avançados 27 (79), 55-66.

» Scaringella, R. S. (2001). A crise da mobilidade urbana em São Paulo. São Paulo Perspectivas, São Paulo 15 (1), 55-59.

"Smeed, R. J. (1968). Traffic studies and urban congestion. Journal of Transport Economics and Policy 2 (1), 33-70.

»Smith, B. L., y Demetsky, M. J. (1997). Traffic flow forecasting: comparison of modeling approaches. J. Transp. Eng. 123, 261-266.

» Tischer, V., Espinoza, H. C. F., y Marenzi, R. C. (2013). Indicadores socioambientales aplicados en la gestión de ambientes costeros. Caso de estudio Santa Catarina, Brasil. Investigaciones Geográficas - Instituto de Geografía. Universidad Nacional Autónoma de México. 86, 53-66.

» TRB - Transportation Research Board. (2000). Highway Capacity Manual. National Research Concil.Executive Committee. 1207p. 
»Vasconcellos, E. A. (2000). Trasnporte urbano nos países em desenvolvimento: reflexões e propostas. São Paulo: Anablume 4 ed.

\section{Vinicius Tischer / tischer@edu.univali.br}

Engenheiro Ambiental e Mestre em Ciências e Tecnologia Ambiental pela Universidade do Vale do Itajaí (UNIVALI), doutorando em Ciências e Tecnologia Ambiental (UNIVALI). Desenvolve pesquisa sobre mobilidade urbana sustentável.

\section{Marcus Polette / mpolette@univali.br}

Pesquisador e professor da Universidade do Vale do Itajaí - UNIVALI. Doutorado em Ecologia e Recursos Naturais (UFSCar). Realiza pesquisas na área de gestão ambiental integrada, sustentabilidade e ciudades inteligentes. 